\title{
Modeling and Testing Miniature Torsion Specimens for SiC Joining Development
} Studies for Fusion

\author{
C. H. Henager, Jr. ${ }^{*}$, B. N. Nguyen ${ }^{1}$, R. J. Kurtz ${ }^{1}$, T. J. Roosendaal ${ }^{1}$, B. A. Borlaug ${ }^{1}$; M. \\ Ferraris $^{2}$, A. Ventrella ${ }^{2}$; and Y. Katoh ${ }^{3}$ \\ ${ }^{1}$ Pacific Northwest National Laboratory, Richland, WA, USA \\ ${ }^{2}$ Politecnico di Torino, Torino, Italy \\ ${ }^{3}$ Oak Ridge National Laboratory, Oak Ridge, TN, USA
}

\begin{abstract}
The international fusion community has designed a miniature torsion specimen for neutron irradiation studies of joined $\mathrm{SiC}$ and $\mathrm{SiC} / \mathrm{SiC}$ composite materials. Miniature torsion joints based on this specimen design were fabricated using displacement reactions between $\mathrm{Si}$ and $\mathrm{TiC}$ to produce $\mathrm{Ti}_{3} \mathrm{SiC}_{2}+\mathrm{SiC}$ joints with $\mathrm{SiC}$ and tested in torsion-shear prior to and after neutron irradiation. However, many miniature torsion specimens fail out-of-plane within the SiC specimen body, which makes it problematic to assign a shear strength value to the joints and makes it difficult to compare unirradiated and irradiated strengths to determine irradiation effects. Finite element elastic damage and elastic-plastic damage models of miniature torsion joints are developed that indicate shear fracture is more likely to occur within the body of the joined sample and cause out-of-plane failures for miniature torsion specimens when a certain modulus and strength ratio between the joint material and the joined material exists. The model results are compared and discussed with regard to unirradiated and irradiated test data for a variety of joint materials. The unirradiated data includes $\mathrm{Ti}_{3} \mathrm{SiC}_{2}+\mathrm{SiC} / \mathrm{CVD}-\mathrm{SiC}$ joints with tailored joint moduli, and includes steel/epoxy and CVD-SiC/epoxy joints. The implications for joint data based on this sample design are discussed.

\footnotetext{
*Corresponding author. Tel. +1 (509) 371-7295

E-mail address: chuck.henager@pnnl.gov (C.H. Henager, Jr.)
} 


\section{Keywords}

SiC; Fusion Materials; Joining; Torsion; Damage Model; Finite Element 


\section{Introduction}

Joining of SiC and SiC-composites has been identified as a critical technology for the use of these materials in either future fusion reactors or in fission power reactors [1-7]. The international fusion materials community is currently irradiating and testing several joint types and compositions in the High Flux Isotope Reactor (HFIR) reactor at Oak Ridge National Laboratory (ORNL) [1]. Pacific Northwest National Laboratory (PNNL) is working with Politecnico di Torino (POLITO) and ORNL using miniature torsion specimens, also referred to as torsion hourglass samples, that have been specifically designed for joint shear strength testing using small irradiation volumes (see Fig. 1) [8]. Ceramic joints and joint shear testing have been studied for many years and several shear joint tests have been designed for ceramics and ceramic composites [4, 7, 9-13]. These include shear lap tests [14], asymmetric 4-point bend tests [11, 15], and double notch shear tests [16, 17]. Each of these tests has some disadvantages; including stress concentrations leading to non-uniform shear stresses [17-19] that create large uncertainties in shear strength values. In addition, these test specimens are all quite large, or conversely are not miniature-type tests, whereas irradiation volumes are small and demand miniature specimen designs. The miniature torsion geometry, therefore, was designed to provide a test specimen consistent with small irradiation test volumes associated with in-reactor irradiation testing [3, 8, 20-24] and to provide a more consistent shear strength test. The experimental data for some joint configurations revealed excellent data reliability and reduced data scatter $[21,24]$ for this specimen design. However, recent high-strength joints fabricated for SiC and SiC-composites have revealed that this test specimen design also has some problems [20, 22, 23], namely out-ofplane fractures that fail to provide simple shear strength values. Since the miniature torsion test appears to be reliable under certain conditions, but not others, and since this design is ideal for 
testing many joints in a small irradiation volume, a mechanical model of this joint was created to help understand the observed shear failures under a range of simulated conditions.

The PNNL joints, which are synthesized using displacement reactions between $\mathrm{TiC}$ and $\mathrm{Si}$, are observed to fail out-of-plane, or in the base SiC material, during torsion testing [1], similar to what others had observed for high-strength joints [20, 22, 23]. Most of the types of joints reported in Ref. [1] exhibited out-of-plane or base material failures, including the glass ceramic joints from POLITO. This type of failure within the base material, while encouraging with regard to joint strength since it implies that the joint is as strong or stronger compared to the base material, does not allow accurate comparisons between types of joints, tailored joints, or failed joints. In particular, post-irradiation joint testing reported in Ref. [1] clearly showed some issues related to the shear strength measurement of several different strong joints. Some observations were consistent with irradiation-induced joint damage and, in the case of the PNNL displacement reaction joint and of glass-ceramic (CA) joints, a fracture mode change from base material to inplane of the joint was observed that could be interpreted with an appropriate model [1].

Therefore, this study was undertaken to determine 1) if some simple modifications to the miniature torsion specimen could be used to address this problem and 2) if a mechanics-based model could better quantify the joint failure response. The first step was to modify the specimen geometry to reduce the joined surface area of the torsion samples in order to understand the effects of fracture initiation on the outer annulus versus an inner annulus and the complex effect of total joint surface area on fracture. The second step was to create a finite element model of the miniature torsion specimen with parameters that could be varied over the wide range of tested materials from POLITO $[3,20,21,24]$. This study will also use the model results to discuss the 
recent data set obtained at ORNL using the HFIR test reactor and the pre- and post-irradiation test results from several joints [1].

\section{Experimental}

\subsection{Miniature Torsion Specimen and Modifications}

The standard miniature torsion specimen (Fig. 1) was used for the majority of the tests reported here, designated as full-bonded joints and referred to as torsion hourglass samples (THGs). Reduced area annular joints were made by dimpling one of the surfaces with either a 2.3 or 3.1-mm diameter diamond slurry drill and are referred to as reduced-area torsion hourglass samples (RATHGs) ${ }^{\dagger}$. These joined samples were fabricated at PNNL (see below) and tested at POLITO. Separately, THG joints were fabricated for HFIR testing and those joints have been irradiated and tested at ORNL and reported in Ref. [1]. No RATHG specimens were prepared for HFIR testing.

\subsection{Joint Synthesis}

\subsection{1 $\mathrm{Ti}_{3} \mathrm{SiC}_{2}+\mathrm{SiC}$ Joints}

Strong joints between miniature torsion halves of chemical vapor deposited (CVD) SiC (CVD-SiC) were made using solid-state displacement reaction joining methods discussed previously [2, 25]. Fully dense joints are processed in pure argon at $1425^{\circ} \mathrm{C}(1698 \mathrm{~K})$ for $2 \mathrm{~h}$ at either 30 or $40 \mathrm{MPa}$ of applied pressure using tape cast powders of $\mathrm{TiC}+\mathrm{Si}$ as a bond layer between the CVD-SiC halves. Joints were observed to consist of a dual-phase interpenetrating microstructure with SiC-platelets interpenetrating $\mathrm{Ti}_{3} \mathrm{SiC}_{2}$ particles with about $40 \%$ SiC by area

\footnotetext{
${ }^{\dagger}$ RATHG is the same as torsion-ring hourglass samples (TRHG) in Ref. [21].
} 
fraction analysis [2]. The joints are strongly bonded at the CVD-SiC/Ti ${ }_{3} \mathrm{SiC}_{2}+\mathrm{SiC}$ interface due to the in-growth of $\mathrm{SiC}$ from the CVD-SiC during the displacement reaction processing, which is explained by the CVD-SiC surfaces being favorable nucleation sites for the SiC-phase produced during the displacement reaction. Additionally, joining pressures of 5, 10, and $20 \mathrm{MPa}$ were also used to produce porous joint test samples in comparison to the fully dense joints from the higher synthesis pressures of 30 and 40 MPa. THG joints were made as shown in Fig. 1. A circular dimple of 2.3 or 3.1-mm diameter was placed in one of the joint halves to create the RATHG samples as shown in Figure 2. These joints, both the reduced joining-pressure joints and the RATHG joints, were created to help understand in more detail test difficulties that were occurring with the miniature torsion joint specimens when joint strength is high [1, 20, 25].

\subsubsection{Adhesive Epoxy Joints}

As discussed in Refs. [21, 24] THG joints were made using Araldite AV119 epoxy between CVD-SiC and between a Type 316-grade stainless steel. AV119 was used to bond these materials after acetone and ultrasonic cleaned surfaces were prepared. The epoxy was cured for 1 $\mathrm{h}$ at $130^{\circ} \mathrm{C}(403 \mathrm{~K})$ [24]. The torsion tests for these epoxy-joined THG samples were performed in the same manner as all the other torsion testing. In addition, simple compressions tests were performed [21] on cylinders of cured AV119 epoxy to establish the mechanical properties of this toughened adhesive material [26, 27].

\section{3 $\quad \mathrm{Ti}_{3} \mathrm{SiC}_{2}+\mathrm{SiC}$ Joint Microstructures and Porosity}

Representative joints synthesized at each of the five joining pressures were cross-sectioned and examined using optical (OM) and scanning electron microscopy (SEM). Representative SEM images of these joints are shown in Figure 3 for each of the applied joining pressures. The porosity content as a function of joining pressure was determined using standard metallographic 
methods. Pores in these materials were separated from the dual phase microstructure based on image contrast and the area fraction determined. The data for each type of joint is shown in Table 1. The joint porosity was used to compute an effective elastic modulus based on the relation

$$
E=E_{0} e^{-C V_{p}}
$$

where $E$ is Young's modulus, $V_{p}$ is volume fraction porosity (measured area fraction), and $C$ is a constant that is equal to 3.57 for CVD-SiC [28]. Although this equation is used for the joint material $\mathrm{Ti}_{3} \mathrm{SiC}_{2}+\mathrm{SiC}$ and $C$ for this material is not known we will use the value of $C=3.57$ for these estimates of modulus reduction due to porosity. The dense Young's modulus for the joint material is estimated to be $E_{0}=341 \mathrm{GPa}$ and that for dense CVD-SiC is $460 \mathrm{GPa}$ [28]. From Table 1 it can be seen that the effective joint moduli range from 340 for a fully dense joint synthesized at $40 \mathrm{MPa}$ joining pressure to $116 \mathrm{GPa}$ for a 5-MPa joint. These data are plotted in Figure 4 as effective moduli as a function of joining pressure. These data will be more meaningful when the joint fracture model is discussed. Note also that the reduced pressure joints are thicker than the fully dense joints (Fig. 3).

\subsection{Joint Testing}

Miniature THG and RATHG unirradiated joint tests were performed at POLITO using a universal testing machine (Zwick 100), where the load was applied using a rotating disk fixture until fracture occurred. The crosshead speed was $0.5 \mathrm{~mm} /$ minute with an estimated rotation speed of about $0.010 \mathrm{rad} / \mathrm{minute}$. The torque was obtained using the force measured at specimen fracture. No stress concentration factor caused by the curvature radius was used in this work. Joint failure locations were noted and samples imaged optically and in an SEM after testing. The torsion testing was carried out at ambient temperature and the results are reported in terms of 
shear strength with notations as to the location of failure or fracture. Joints that fail by shattering the sample, which happens most often, should be considered as having a strength that is better defined as the torsion resistance of these joined structures, and they can be safely used to compare torsional failure resistance of SiC THGs joined by several different materials. However, the term shear strength will be used instead of torsion resistance of joined structure for brevity [1]. The shear strength, or torsional resistance, is approximated by using Eq. 2, which is valid for single-phase, linear elastic materials [29] with no stress concentration ${ }^{\ddagger}$ :

$$
\tau=\frac{16 T}{\pi d^{3}}
$$

where $T$ is the applied torque at fracture and $d$ is the diameter of the joined circular region, which is $5 \mathrm{~mm}$ for the full bonded joints. For annular bonded joints, or RATHG joints, the following expression is used:

$$
\tau=\frac{16 T d}{\pi\left(d^{4}-d_{i}^{4}\right)}
$$

where $d_{i}$ is the inner annulus diameter. These expressions are used to approximate the shear strength regardless of the failure location. It is important to note that the use of Eqs. 2 and 3 provide only rough approximations of the shear strength of THG specimens with dissimilar joints [29]. Finite element analysis using a damage model will allow more accurate descriptions of stresses, strains and damage evolution in the specimen, and therefore will enable more accurate strength prediction.

\footnotetext{
‡ Strictly speaking, Eq. 2 should contain a stress concentration factor appropriate for the THG
} geometry as discussed in Ref. [29]. 


\section{Model Formulation}

\subsection{Approach}

This section summarizes the construction of elastic-damage and elastic-plastic damage models and computational method for predicting failure initiation and propagation [30, 31] in the joined specimens. The models consider the joined material, either CVD-SiC or steel, together with a thin joint region consisting of either $\mathrm{Ti}_{3} \mathrm{SiC}_{2}+\mathrm{SiC}$ of varying modulus and strength or an epoxy. The epoxy-bonded steel specimens simulate samples made and tested at POLITO to help validate the miniature torsion specimen [21, 24]. The models are constructed by considering damage in elastic and in elastic-plastic damageable materials that can be described by a scalar damage variable, $D$, and can be related to the microcrack density or microcrack volume fraction, or simply a parameter that governs the reduction of the elastic stiffness to phenomenologically quantify the level of damage accumulation in the material [31]. In this paper these damage models will be used phenomenologically to simulate fracture in THGs depending on the given material parameters.

\subsubsection{Elastic Damage Model}

Damage affects the material stiffness according to a stiffness reduction law:

$$
C_{i j k l}=C_{i j k l}(D)
$$

Using the concepts of thermodynamics of continuous media [31, 32], a thermodynamic potential is defined to derive the constitutive relations and the thermodynamic force (as a conjugate variable) associated with the damage variable. This damage model uses the density of the elastic deformation energy as the thermodynamic potential that provides a coupling between damage and elasticity 


$$
\Phi\left(\varepsilon_{i j}, D\right)=\frac{1}{2} C_{i j k l}(D) \varepsilon_{i j} \varepsilon_{k l}
$$

From the potential in Eq. 5, the constitutive relations and the thermodynamic force associated with $D$ are obtained as

$$
\begin{gathered}
\sigma_{i j}=\frac{\partial \Phi\left(\varepsilon_{i j}, D\right)}{\partial \varepsilon_{i j}}=C_{i j k l}(D) \varepsilon_{k l} \\
F=\frac{\partial \Phi\left(\varepsilon_{i j}, D\right)}{\partial D}=\frac{1}{2} \frac{\partial C_{i j k l}(D)}{\partial D} \varepsilon_{i j} \varepsilon_{k l}
\end{gathered}
$$

where $\sigma_{i j}$ and $\varepsilon_{i j}$ denote the stress and strain tensors, respectively. As damage is an irreversible process, the Clausius-Duhem inequality that expresses the total dissipation must be positive [32].

$$
-F \cdot \dot{D} \geq 0
$$

From the inequality in Eq. 8, it is clear that if $F<0$, then $\dot{D}>0$ : damage progresses. If $F \geq 0$ then $\dot{D}$ must be zero, and damage is stable. Finally, using a damage criterion dependent on a damage threshold function [33], $F_{\mathrm{c}}(D)$

$$
f(D)=F_{\mathrm{c}}(D)-F
$$

the damage evolution law is obtained by the consistency condition: $f=0$ and $\mathrm{d} f=0$

$$
\mathrm{d} D=\frac{-\frac{\partial C_{i j k l}(D)}{\partial D} \varepsilon_{i j} \mathrm{~d} \varepsilon_{k l}}{\frac{1}{2} \frac{\partial^{2} C_{i j k l}(D)}{\partial D} \varepsilon_{i j} \varepsilon_{k l}-\frac{\partial F_{c}(D)}{\partial \mathrm{D}}}
$$


If the elastic modulus is assumed to be reduced by damage in a linear manner,

$E(D)=E^{0}(1-D)$ with $E^{0}$ being the initial elastic modulus, the damage evolution law in Eq. 10 becomes

$$
\mathrm{d} D=\frac{\frac{\partial C_{i j k l}(D)}{\partial D} \varepsilon_{i j} \mathrm{~d} \varepsilon_{k l}}{\frac{\partial F_{\mathrm{c}}(D)}{\partial \mathrm{D}}}
$$

Damage evolves with the deformation according to the damage evolution law until a critical (saturation) state at which $D=D_{\text {cr }}\left(0<D_{\text {cr }}<1\right)$ and failure occurs. $D_{\text {cr }}$ is small for brittle materials, and this is the case for ceramic materials studied in this work. The occurrence of failure implies that the failed material can no longer carry loads. In this work, failure at damage saturation ( $D=D_{\text {cr }}$ ) leading to crack initiation and propagation is modeled by a vanishing finite element technique [34] that reduces the stiffness and stresses of the failed "integration points" of an element to zero in number of load steps according to the Nguyen et al.'s model [30, 35]

$$
\begin{aligned}
& n<K: \quad C_{i j k l}^{\text {failed }}=C_{i j k l}\left(D_{\text {cr }}\right)-\frac{n C_{i j k l}\left(D_{\text {cr }}\right)}{K} \\
& n \geq K: \quad C_{i j k l}^{\text {failed }}=\alpha_{i j k l} \\
& \sigma_{i j}=C_{i j k l}^{\text {failed }} \varepsilon_{k l}
\end{aligned}
$$

where $n$ is the load step number starting from the step at which failure occurs, and $K$ is a prescribed constant, which represents the crack resistance of the material. The components of $\alpha_{i j k l}$ are taken to be very small ( $\left.10^{-8} \mathrm{MPa}\right)$ to represent a vanishing stiffness. The patterns of failed elements represent propagated cracks. 


\subsubsection{Elastic-Plastic Damage Model for 316SS Steel and AV119 Epoxy}

316SS and AV119 epoxy exhibit pronounced nonlinear behaviors controlled by plasticity and damage. Therefore, an elastic-plastic damage description is used in this work to model the nonlinear responses of these materials to monotonic loading up to failure. Specifically, the model used here is from a model used by Nguyen and Kunc [36] that describes the elastic-plastic damage behavior of a thermoplastic matrix in a long-fiber thermoplastic composite. In this model, the modified Ramberg-Osgood relation captures the material nonlinear stress-strain response:

$$
\bar{\varepsilon}=\frac{\bar{\sigma}}{E(1-D)}+\frac{\sigma_{0}}{E}\left(\frac{\bar{\sigma}}{\sigma_{0}(1-D)}\right)^{n}=\frac{\overline{\tilde{\sigma}}}{E}+h \overline{\widetilde{\sigma}}^{n}
$$

where $D$ is the isotropic damage variable, $\bar{\sigma}$ and $\sigma_{0}$ are the equivalent and reference stresses,

respectively. The hardening $h$ is given by $h=\sigma_{0}^{1-n} / E$ where $E$ and $n$ are the elastic modulus and power-law exponent. The "tilde" symbol denotes an effective quantity based on the principle of strain equivalence [37]. The equivalent stress can be expressed in terms of the equivalent plastic strain as:

$$
\bar{\sigma}=(1-D) k\left(\bar{\varepsilon}^{\mathrm{p}}\right)^{1 / n}
$$

where $k=(1 / h)^{1 / n}$ is the hardening coefficient. Using the deformation theory of plasticity and assuming proportional loading, an evolution law for $D$ is sought in terms of stress and plastic strain quantities. To this end, we use the Lemaitre-Chaboche three-dimensional damage model in deformation for isotropic hardening materials [38] that expresses the damage variable increment in terms of the equivalent plastic strain increment as: 


$$
d D=\frac{D_{\mathrm{c}}}{\bar{\varepsilon}_{\mathrm{p}}^{\mathrm{R}}-\bar{\varepsilon}_{\mathrm{p}}^{\mathrm{D}}}\left(\left[\frac{2}{3}(1+v)+3(1-2 v)\left(\frac{\sigma^{\mathrm{h}}}{\bar{\sigma}}\right)^{2}\right] d \bar{\varepsilon}^{\mathrm{p}}\right)
$$

where $\bar{\varepsilon}_{\mathrm{T}}^{\mathrm{J}}$ and $\bar{\varepsilon}_{\mathrm{T}}^{\mathcal{H}^{\prime}}$ are the equivalent plastic strains at damage initiation and at rupture,

respectively, $D_{c}$ is the value of $D$ at rupture, $v$ is Poisson's ratio, and $\sigma^{h}$ the hydrostatic stress.

This elastic-plastic damage model was implemented in ABAQUS via user subroutines to describe the constitutive behaviors of the AV119 joint [27] and of the joined 316SS material [39] in the ABAQUS analyses of THG specimens. The post-failure behaviors are captured by the same vanishing element method as the one used with the elastic damage model (Eq. 12). Table 4 provides the model parameters identified for these materials used in the analyses.

\subsection{Computational Procedure for The Elastic Damage Model}

The damage model was implemented in PNNL's EMTA-NLA tool [40] that functions as a set of user subroutines of ABAQUS ${ }^{\circledR}$. For the execution of the damage model, we must determine a priori the stiffness reduction law, $C_{i j k l}(D)$ in Eq. 4 and the damage threshold function, $F_{\mathrm{c}}(D)$, whose derivatives with respect to the damage variable govern the damage evolution law in Eq. 10. For the materials studied in this work, a linear reduction of the elastic modulus with the damage variable was assumed, and as a result, the stiffness reduction law is directly obtained as

$$
C_{i j k l}=C_{i j k l}^{0}(1-D)
$$

where $C_{i j k l}^{0}$ denotes the initial elastic stiffness tensor of the undamaged material. $C_{i j k l}(D)$ can generally have a more complex expression than this simple linear relationship. For materials with 
distributed damage like microcracks $C_{i j k l}(D)$ can be determined via micromechanical modeling. The damage threshold function $F_{c}(D)$ can be discretely computed for the damage variable values in the $\left[0, D_{\mathrm{cr}}\right]$ interval by means of the thermodynamic force associated with the damage variable in Eq. 9 and the shear stress-strain data. The increment of the damage variable is computed in terms of strains and strain increments using the damage evolution law to update the damage variable for the current loading. Next, the current stresses are computed using the constitutive relations. Damage can evolve with deformation until reaching saturation characterized by $D=D_{\text {cr }}$ for which failure is predicted to occur. Failure is modeled by the finite element vanishing technique associated with the failure model described in the previous section in Eq. 12.

\subsection{Computational Procedure for the Elastic-Plastic Damage Model}

The elastic-plastic damage model was also implemented in PNNL's EMTA-NLA tool [40]. The material stress-strain response is computed incrementally according to:

$$
\Delta \tilde{\sigma}_{i j}=\bar{H}_{i j k l} \Delta \varepsilon_{k l}
$$

where $\Delta \tilde{\sigma}_{i j}$ denotes the effective stress increment [37], $\Delta \varepsilon_{i j}$ and $\bar{H}_{i j k l}$ are respectively the strain increment, and the tangent stiffness tensor that is affected by both plasticity and damage. At each increment, the current tangent modulus is determined from the modified Ramberg-Osgood relation as:

$$
E^{t}=\frac{E}{1+\frac{n E}{k\left(\bar{\varepsilon}^{p}\right)^{1-n / n}}}(1-D)
$$


The values of the damage variable and of the equivalent plastic strain at the beginning of the increment are used to compute $E^{\mathrm{t}}$ that is then used to determine $\bar{H}_{i j k l}$. The computation of the stress increment allows the stress to be updated, and therefore, the effective equivalent stress can be determined by $\overline{\tilde{\sigma}}=\sqrt{\frac{3}{2} \tilde{\sigma}_{i j}^{\prime} \tilde{\sigma}_{i j}^{\prime}}$ with $\tilde{\sigma}_{i j}^{\prime}$ being the deviatoric effective stress components. Finally, the total equivalent strain and equivalent plastic strain are computed using the modified Ramberg-Osgood relation (Eq. 13), and Eq.15 is used to calculate the value of the damage variable increment to update the damage variable. These quantities are saved to start the next load increment until the damage variable attains the critical value at rupture. Failure is predicted to occur when $D=D_{\mathrm{c}}$. The vanishing element technique combined with the failure model is then applied to reduce the material stiffness and stress to zero according to Eq. 12.

\section{Results}

\subsection{Unirradiated Torsion Tests for $\mathrm{Ti}_{3} \mathrm{SiC}_{2}+\mathrm{SiC}$ Joints}

Table 2 lists the unirradiated dual-phase $\mathrm{Ti}_{3} \mathrm{SiC}_{2}+\mathrm{SiC}$ displacement reaction joints that were tested and summarizes the results. Figure 5 is a graph of the results, including the unirradiated THG joints tested at ORNL using similar equipment and test parameters as POLITO. The strong 40 MPa THG joints all fail in the base material such that the entire THG sample is failed and, thus, any strength values are considered as torsional resistance values. For the CVD-SiC material and THG machining conditions used in this study this shear strength value ranges from 80 to 120 MPa. This is true for the RATHG joints as well and these base material failures typically involve fracture of the entire torsion specimen. Figure 6 shows typical sample remnants after such failures. Although the THG machining conditions are not discussed here and are beyond the scope of the present research, it can be seen from Fig. 3 in Ref. [1] that all the joined CVD THG 
samples failed in torsion between 80 and $125 \mathrm{MPa}$ and (see Table 4, Ref. [1]) the majority of these failed in the base CVD material, or out-of-plane. This implies that these THG joined samples machined from CVD-SiC behave similarly and what it is measured is the torsional resistance of CVD-SiC joined THG, independent of the joining material. It is expected that CVD-SiC will behave probabilistically in shear as a brittle material with an unknown flaw distribution in these tests.

For reduced pressure joints it is also observed that base material failures occur for 30 and 20 MPa applied joining pressures, as indicated in Table 2 and Fig. 5. However, for $10 \mathrm{MPa}$ and 5 MPa joining pressures there is a transition from base material failure to true shear in-plane joint failures. For $10 \mathrm{MPa}$ pressure this does not always occur and 1 out of 3 joints fail in the base material in this study. For 5 MPa pressure all of the joints fail in plane with a shear strength of 37 $\pm 16 \mathrm{MPa}$. Figure 7 shows a sample of an in-plane joint failure with joining material bonded to either face of the tested THG CVD-SiC specimen. The experimental data clearly show that weak joints, such as the $5 \mathrm{MPa}$ and some of the $10 \mathrm{MPa}$ reduced joining pressure joints, fail in-plane whereas stronger joints, including those made at $20 \mathrm{MPa}$ joining pressure and higher, only fail in the base material and do not give reliable joint shear strengths.

\subsection{Irradiated Joints}

As indicated and discussed in Ref. [1] four $\mathrm{Ti}_{3} \mathrm{SiC}_{2}+\mathrm{SiC}$-joined THG samples irradiated at $800^{\circ} \mathrm{C}$ to 5 dpa were tested in torsion following irradiation in the HFIR reactor at ORNL. The results of these tests (see Table 4 and Fig. 3 of Ref. [1]) indicate that the torsion failure mode had changed to in-plane with an average shear strength of $98 \mathrm{MPa} \pm 22 \mathrm{MPa}$ compared to a value of $117 \mathrm{MPa} \pm 10 \mathrm{MPa}$ prior to irradiation. In addition, microcracks were observed within the dualphase joint in SEM examinations. Similarly, several CA-CVD glass-ceramic joints also 
debonded and exhibited substantial transverse cracking after irradiation. Shear strengths for these joints was $115 \pm 20$ MPa prior to irradiation with base material failure mode and $93 \pm 6 \mathrm{MPa}$ post-irradiation at $800^{\circ} \mathrm{C}, 5 \mathrm{dpa}$ with a fracture mode transition to in-plane of the joint [1]. The observation of a change in the failure mode, or fracture path, is significant and will be addressed in the discussion.

\subsection{Epoxy Joints}

Adhesive epoxy joints prepared in POLITO [21, 24] routinely failed in the plane of the joint for the joined CVD-SiC and steel and a shear strength of $66 \mathrm{MPa} \pm 10 \mathrm{MPa}$ for both materials was obtained using the THG geometry and Eq. 2. However, separate compression testing of the AV119 toughened adhesive epoxy revealed that this material is not a brittle material, such as the CVD-SiC, and neither is the steel. In this case, Ferraris et al. [21] suggest that the reported values of 66 MPa shear must be reduced to account for the plasticity of the AV119 and, thus, arrive at a value of $36 \mathrm{MPa}$ shear strength for this joint. The model developed here can also be used to address this issue more accurately by treating the materials via the elastic-plastic damage model.

\subsection{Results for Elastic Damage Model}

The damage models are implemented in ABAQUS ${ }^{\circledR}$ for a finite element analysis of the THG joint specimen shown in Fig. 1. In order to investigate specimen failure for different joints, appropriate material properties of the joint were considered and are reflected through the assumed shear stress-strain responses up to failure in the damage models. In addition, typical mechanical properties of CVD-SiC and nominal steel (316SS) as the joined halves that make up the THG in the experimentally observed range were assumed. Damage models have been used to describe microcracking in ceramic materials for many years [41]. The use of a damage model is problematic for a linear-elastic brittle ceramic in tension since, strictly speaking, a critical flaw in 
Mode I loading does not experience any damage accumulation prior to failure, although there are exceptions to this statement throughout the ceramics literature [42-44]. We choose to implement the damage model for brittle ceramics in shear loading. In this case, a flaw under Mode III loading experiences some damage accumulation prior to critical crack growth due to frictional forces on the crack faces and a non-linear shear stress-strain curve results [45]. Furthermore, it is understood that this problem can be addressed using multiaxial loading considerations if a known flaw distribution was available [45-50], but that this is not practicable here. Rather, the damage model approach is used in a phenomenological sense to address the effects of load sharing in this complex joined system. The thermodynamic and continuum damage mechanics (CDM) approach adopted in our paper is phenomenological. It does not describe the detailed frictional sliding of crack ligaments but the magnitude and effect of shear damage on the material response are phenomenologically captured by the damage variable, $D$, driven by the associated thermodynamic force, $F(D)$, and the damage evolution law given by Eqs. 10 and 17, respectively. The damage evolution law depends on the damage threshold function, $F_{c}(D)$, a material property that expresses how resistant to damage the material exhibits until damage saturation.

Figure 8 and Table 3 present the mechanical properties in shear assumed in this parametric study. There are 5 different behaviors (denoted by case study numbers 1 through 5) considered for the $\mathrm{Ti}_{3} \mathrm{SiC}_{2}+\mathrm{SiC}$ composite joint differentiated by their calculated modulus and assumed failure strength. In addition, a similar analysis was performed for epoxy joined CVD-SiC specimens. The damage variable value at saturation was taken to be 0.2 for all the ceramics while it was considered to be 0.4 for the brittle epoxy (case 6) leading to an epoxy shear strength of 47 MPa and shear failure strain of 0.0203 . 
Figure 9 shows the three-dimensional (3D) finite element model with assigned material behaviors for the analysis of the THG joint specimen (Fig. 1). The joint was assumed to be 10 microns thick and was finely discretized. The top and bottom regions of the THG specimen were modeled assuming elastic CVD-SiC material while the central region includes the elastic damage CVD-SiC regions joined by an elastic damage $\mathrm{Ti}_{3} \mathrm{SiC}_{2}+\mathrm{SiC}$ layer or other joining layer. The bottom surface $(y=0)$ of the specimen was completely fixed (zero-displacements and zerorotations). Zero-normal displacement and uniform rotation about the specimen vertical axis were imposed on the top surface to achieve the torsion loading about this axis. Figure 9b shows the computed Von Mises equivalent stress contours in the entire THG specimen for Case 1 resulting from the application of the boundary conditions at a loading level prior to the onset of cracking. The view shows the contours through a cutting plane perpendicular to the $\mathrm{z}$-axis and clearly shows the stress distribution in the whole structure with the expected stress concentration in the fillet neck region of the THG sample. Thus, the applied torque is concentrated in the plane of the joint and the torsion shear stresses are maximum at the outer fillet surface in the neck region. With increasing torsion loading, stress concentrations in this region lead to damage and failure of the specimen.

Figure 10a shows the damage distribution (contour of the damage variable) in the specimen with the fully dense $\mathrm{Ti}_{3} \mathrm{SiC}_{2}+\mathrm{SiC}$ (case 1) joint at the initiation of fracture in the THG specimen. This joint material is slightly less stiff, but slightly stronger than the CVD-SiC (Table 3). Failure is predicted to occur when the computed damage attains a critical value. A close examination of the fracture initiation region (Fig. 10c) reveals that fracture is predicted to occur in the CVD-SiC and not in the joint since the values of the damage variable are well below the critical value within the joint layer. Fig. 10c shows an advanced state of fracture where the failed regions 
extended deeper in the CVD-SiC joined materials. The predicted fracture location, i.e. in the CVD-SiC THG material, agrees well with experimental fracture observations for this type of strong joint. These joints are observed to exhibit out-of-plane fracture of the base CVD-SiC material and this has been documented [1, 3, 8, 20, 22, 23] by many others.

Figures $11 \mathrm{a}$ and $11 \mathrm{~b}$ show the distributions of shear stresses $\tau_{r t}$ and $\tau_{t z}$ in and around the fracture region shown in Fig. 10c (Case 1). These stresses are expressed in the cylindrical coordinate system $r t z$ with the $z$-axis coinciding with the specimen axial direction. These stresses are the stresses that will fracture this specimen. The stresses vanish in the completely failed areas and stress concentrations move inside the specimen with crack (damage zone) advance. Stresses $\tau_{r t}$ are antisymmetric about the joint plane as the torsion via the rotation applied on the specimen top surface is parallel to the joint plane. Stresses $\tau_{t z}$ are also important and their distribution is symmetric with respect to the axial direction and the joint plane. The other shear stress component $\tau_{r z}$, and normal stresses $\sigma_{r r}, \sigma_{t t}$, and $\sigma_{z z}$ are very small and are not shown here as their contributions to the material fracture are negligible. Fig. 11c shows the equivalent Von Mises stress contour resulting mainly from the contributions of the shear stresses $\tau_{r t}$ and $\tau_{t z}$ given in Figs. 11a and 11b. Fig. 11d shows the deformation energy density contour corresponding to the stress distributions given in Figs. 11a, 11b and 11c and clearly shows that the deformation energy is accumulated in the CVD-SiC material as damage and fracture mainly develop in this material, with very little in the joint region. As will be discussed in more detail below, this is a consequence of load sharing between the CVD-SiC base material and the joint layer such that the volume of highly stressed CVD-SiC is significantly larger than the joint layer and the shear stresses are higher. 
Similar analyses were conducted for all the THG joint specimens made of the simulated materials listed in Table 3, which are based on the calculated modulus values listed in Table 1, although the CA-CVD joints were not analyzed here. In Figure 12 the most porous $\mathrm{Ti}_{3} \mathrm{SiC}_{2}+\mathrm{SiC}$ joint (case 5) is shown and the difference between this predicted result and that shown in Fig. 10 is remarkable. The elastic damage model now predicts that the THG sample will fail along the joint line as has been observed (see Fig. 7) during the testing in POLITO. The predicted failure patterns for all the studied cases are gathered in Figure 13. Cases 1 and 5 for the $\mathrm{Ti}_{3} \mathrm{SiC}_{2}+\mathrm{SiC}$ joint have been discussed above. Cases 2 and 3 represent $\mathrm{Ti}_{3} \mathrm{SiC}_{2}+\mathrm{SiC}$ joints made at $30 \mathrm{MPa}$ and $20 \mathrm{MPa}$ applied pressures, respectively, which are increasingly less stiff than the joined CVD-SiC. For both of these cases, failure is predicted to initiate in the joint but then develop into

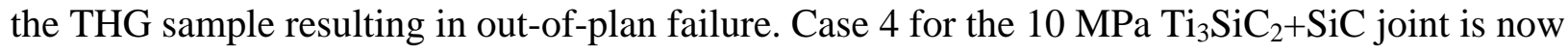
only about $1 / 3$ as stiff as the CDV-SiC and the simulation indicates a mixture of failure within the joint and within the THG sample. Experimentally, these 10 MPa joints sometimes fail within the joint (Fig. 5). Case 5 is predicted to fail within the joint and experiments confirm this failure mode (Figs. 5 and 7). The simulated brittle epoxy joint (Case 6) always exhibits in-plane failure. The results illustrated in Fig. 13 predict that there is a joint-to-CVD-SiC modulus and/or strength ratio below which the fracture mode switches from out-of-plane failure to in-plane failure, which is in agreement with our observations as shown in Table 2 and Fig. 5.

\subsection{Results for Elastic-Plastic Damage Model for $316 S S$ and AV119}

As recognized by Ferraris et al. [21] the toughened adhesive epoxy AV119 is not a brittle material but behaves as an elastic-plastic material and, therefore, must be treated accordingly. Figure 14 and Table 4 together with the elastic-plastic damage model provide the necessary tools to address this issue. The results of the elastic-plastic damage model simulations of the 316SS 
and AV119 epoxy stress-strain curves shown in Fig. 14 demonstrate the ability of this model to capture the nonlinear stress-strain behaviors of these materials caused by plasticity coupled with damage.

In addition to using an elastic-plastic damage model, the joint thickness was modified to more closely simulate the work performed in POLITO. Figure 15 shows the predicted failure locations for a 50- $\mu$ m thick AV119 joint between CVD-SiC and 316SS. The CVD-SiC is treated elastically as before but in this case the AV119 and 316SS are treated using the elastic-plastic model. The model results agree with the experimental torsion tests, namely, that the THG specimens fracture in the plane of the joint when bonded using AV119 adhesive epoxy regardless of the THG specimen material. These results are expected to be more accurate and realistic than treating the epoxy as a brittle joining material.

\section{Discussion}

\subsection{Model Predictions and Comparisons}

The damage models were created to help understand the fracture results from the THG specimens that exhibited non-planar fracture that was not truly reflective of joint properties. Rather, the literature refers to this data as "torsional shear resistance” of the THG [1, 3, 8, 20, 22, 23] when the THG specimen fails in the base material, or out-of-plane. The critical part of the damage models was to be able to simulate the stress-strain curves for the constitutive materials; otherwise the models would not be reasonable. The curves shown in Fig. 8 using the data in Table 3 capture the material elastic constants as well as the failure strengths and are reasonable assumptions. In addition, the stress-strain responses computed by the elastic-plastic damage model shown in Fig. 14 correctly capture the stress-strain behavior of both the 316SS steel and AV119 epoxy. The accuracy of the THG damage modeling is predicated on the accuracy of the 
individual constituent's stress-strain data and, even though this model data is not completely precise, the results from carefully applying the model are expected to show the desired effects.

The models, both the elastic damage and elastic-plastic damage approaches, capture the key observations, namely that there is a transition from planar to non-planar fracture over a range of elastic moduli and strength values. High strength and high moduli materials are predicted to fail out-of-plane and within the base THG material, whereas low modulus materials fail in the plane of the joint. Intuitively, it is anticipated that low modulus epoxy will behave differently compared to high modulus $\mathrm{Ti}_{3} \mathrm{SiC}_{2}+\mathrm{SiC}$ or CA glass-ceramic in terms of load sharing with the CVD-SiC base material. In fact, one thought (gedanken) experiment is to imagine the entire miniature torsion specimen machined from a single piece of CVD-SiC and then to predict where it will fail. Probabilistic brittle fracture mechanics predicts that it will fail somewhere in the specimen that contains a combination of the largest flaw and the highest tensile/shear stresses, which will not necessarily coincide with the central plane of the torsion specimen. Thus, a high strength, high modulus joint may not fail in the plane of the joint either. As shown in Figs. 10 and 11 load sharing with the CVD-SiC forces a majority of the damage for high modulus joints to occur within the base CVD-SiC material and failure is predicted to occur out-of-plane of the joint. However, this load sharing is a function of the constitutive behavior (i.e., modulus, stressstrain response, etc.) differences between the joint and base THG material. The model predicts a high degree of load sharing and CVD-SiC damage for a joint modulus greater than about 200 GPa and a minimal amount of load sharing with highly localized (planar) fracture for moduli 100 GPa and lower (Fig. 13). This is in good agreement with the observed experimental data for the THG joints tested at POLITO (Fig. 5). 
Figure 16 shows the computed maximum shear stresses at the neck of the specimen and in a plane perpendicular to the specimen vertical axis for all the cases studied in this work. The maximum shear stress is highest (104 MPa) for the specimen with the $\mathrm{Ti}_{3} \mathrm{SiC}_{2}+\mathrm{SiC}$ stiffest and strongest joints, cases 1, 2, and 3. Cases 4 and 5 have shear strengths that are smaller than this and, in the simulation, reflect the shear strength of the joint. In addition, the predicted failure strengths in shear shown in Fig. 16 match quite well with measurements from ORNL and POLITO $[1,20]$. The ORNL data for the unirradiated $\mathrm{Ti}_{3} \mathrm{SiC}_{2}+\mathrm{SiC}$ joints indicated a torsional shear resistance value of $117 \mathrm{MPa} \pm 10 \mathrm{MPa}$, which agrees well with the model prediction of 104 MPa [1]. It is noted that this predicted strength value follows from the CVD-SiC damage model determined from the assumed CVD-SiC mechanical properties. Thus, the model predicts that the torsion test will fail in the CVD-SiC material and that the torsional shear resistance of the sample will be $104 \mathrm{MPa}$ because that is the predicted shear strength of the CVD-SiC simulated here. This failure stress could be increased if stronger base material was provided. Note that the NITE materials tested in Ref. [1] fail at much higher shear strengths compared to the CVD-SiC and this is attributed to the higher shear strength of the NITE SiC. However, the main point is that for certain material combinations the THG test will fail at the shear strength limit of the base material and will not provide information regarding the shear strength of the joint material. This is observed in the THG testing and is predicted by the elastic damage model.

The epoxy joined data from POLITO is more complex. Results indicate a shear fracture strength of $36 \mathrm{MPa}$, which agrees well with the model prediction of about $38 \mathrm{MPa}^{\S}$ for the brittle

\footnotetext{
$\S$ Personal Communication from Prof. M. Ferraris of Politecnico di Torino. They used AV119 Epoxy with an elastic modulus of 2.8 GPa and Poisson ratio of 0.4. They obtained accurate, in-plane shear failures for all tests and a shear strength of $36 \mathrm{MPa} \pm 8 \mathrm{MPa}$.
} 
epoxy material (Case 6 and Fig. 16a). In this case, where the epoxy modulus is only a fraction of the CVD-SiC or 316SS the fracture path is in the plane of the joint in the epoxy material. Thus, this test will measure a true shear stress value. However, since AV119 toughened adhesive epoxy is not a linear elastic brittle material, the elastic damage model is not appropriate and an elasticplastic damage model was developed based on mechanical property data for AV119 and 316SS as discussed. This model predicts a shear failure strength of $28 \mathrm{MPa}$ for a 50- $\mu \mathrm{m}$ thick joint region of AV119 (Figs. 16a and 16b), which is less than the POLITO calculated value of $36 \mathrm{MPa}$ but is in agreement with the measured asymmetric 4-point bending for epoxy-joined SiC [21]. However, Ferraris et al. also report a value of $66 \mathrm{MPa} \pm 10 \mathrm{MPa}$ for AV119-joined THG CVD$\mathrm{SiC}$ specimens where the shear strength is calculated using Eq. 2, which is inappropriate as discussed in Ref. [21]; rather it is suggested that this value be reduced and a value of $36 \mathrm{MPa}$ is suggested as a more accurate value, which is in general agreement with the results here of 28 MPa. It is also noted that this prediction is based solely on the accuracy of the assumed mechanical properties of AV119 adhesive epoxy taken from Ref. [27]. Since the strength of AV119 depends on the curing time and temperature, etc., the value determined by the elasticplastic model here might differ from other AV119 data. However, the approach developed here is a much-improved methodology for analyzing miniature torsion test results in the future.

\subsection{Data Interpretation and Torsion Test Future}

Since the model predicts that high strength, high modulus joints will likely not fail so as to provide a true shear strength for the joints then an obvious point of discussion is what to make of the miniature torsion test? First, the THG specimen is ideal for small-volume, in-reactor experiments and provides a vehicle for obtaining valuable microstructural evolution data for experimental joints. The THG specimen can still provide microstructural evolution leading to 
differential strains, environmental exposures, and radiation damage. This became clear in the HFIR data recently obtained at ORNL [1]. In that respect, the miniature THG specimen is a successful design.

Second, changes in joint strength or moduli due to radiation damage can be revealed during post-irradiation joint testing. It is worth noting that the $\mathrm{Ti}_{3} \mathrm{SiC}_{2}+\mathrm{SiC}$ joints survived after $800^{\circ} \mathrm{C}$ (1073 K) and 5 dpa but that the torsion failure location changed from CVD-SiC base material failure to in-plane joint failure as noted in Ref. [1]. This suggests that a major change occurred in the joined specimens and post-irradiation microscopy revealed a degree of interface cracking and microcracking within the joint material. This is thought to be due to either thermal expansion or swelling mismatches between the joint material and the CVD-SiC and/or within the dual-phase joint material. A similar argument can be advanced for the CA glass-ceramic joints. Thus, both shear strength and shear failure location can be used to help understand joining for fusion materials. The role of the model in this understanding can be to guide experimental data interpretation by allowing various parameters to be controlled and varied. It is important to realize that many of these parameters can also be independently quantified so that the model can be refined as needed.

The in-reactor irradiation results from ORNL also display a failure mechanism that is not included in the model yet, namely, the failure of the joint/CVD-SiC interface. Both the $\mathrm{Ti}_{3} \mathrm{SiC}_{2}+\mathrm{SiC}$ joints and the CA glass-ceramic joints exhibited some form of interface fracture located at the joint/CVD-SiC interface. The model here assumes a strongly bonded interface between the joint and CVD-SiC and no evolution of that bond is allowed in the FE model. Future model implementations will treat the interface as a separate material region with an identifiable strength. 
The torsion shear test is an example of a seemingly simple mechanical test that is, in reality, a complex multiaxial loading problem and methods exist to address these problems in terms of strengths and failure probabilities [45-50]. For future reference, if flaw distributions were known for CVD-SiC and for the joint materials, plus flaws at the joint/CVD-SiC interface, then a true multiaxial, probabilistic solution to the THG specimen could be implemented. However, such an approach is outside of the scope of this study and would be extremely challenging to implement given the complex materials involved in these prototypical fusion reactor joints since determining the actual flaw distributions would be a difficult task. Still, the transition from outof-plane, base CVD-SiC failure to in-plane joint failures that was observed in the post-irradiation testing of these joints most likely indicates a change in the joint flaw distribution due to the irradiation exposure. Significantly, new flaws were observed in post-irradiation SEM examinations of these joints [1].

Finally, it is noted that for a THG specimen previously subjected to neutron irradiation, the experimentally determined irradiated elastic properties can be used to compute the initial elastic stiffness of the irradiated material, and knowing thermal expansion coefficients and the temperature change right after irradiation, thermal stresses can be computed that represent the residual stresses before any mechanical actions (i.e., applied torsion loading). Exactly the same kind of finite element analysis of the THG specimen subjected to torsion loading can be applied here to elucidate how important the contribution of residual stresses is on the onset of cracking, crack propagation, and shear strength of the irradiated THG specimen. This manuscript does not address the effects of residual stress or the effects of neutron damage, such as differential swelling leading to irradiation-induced stresses, even though it is anticipated that these will be significant, since at this time these effects are not known with certainty for any of these joined 
material combinations. This level of detail can certainly be implemented in the model presented here but will be reserved for a future study.

\section{Conclusions}

Miniature torsion specimens, referred to as THG specimens, often fail within the joint body or out-of-plane of the joint plane when the THG material is a ceramic, such as CVD-SiC, and the joint is strong. This study developed elastic and elastic-plastic damage models that demonstrated that for a wide range of joint moduli and strengths that out-of-plane failure is predicted in agreement with observations until the modulus of the joint material falls below about $1 / 3$ of the CVD-SiC modulus. The model indicates that out-of-plane fracture is due to load sharing between the joint material and the CVD-SiC causing high shear stresses to develop within the neck region of the THG CVD-SiC (or other ceramic) that surpass its shear strength. Since these fractures are probabilistic in nature, there is no guarantee that failures will occur within the plane of a joint for strong, stiff ceramic or glass-ceramic joints. In fact, since the highly stressed volume of the THG base material is much greater than the volume of the joint material this almost guarantees that for strong, stiff joints failure will occur within the joined ceramic base material. This finding is documented by many such tests with $\mathrm{Ti}_{3} \mathrm{SiC}_{2}+\mathrm{SiC}$ joints that are stronger and almost as stiff as CVD-SiC THG material. Without exception, out-of-plane failure modes were observed for these joints tested in torsion when the base material was CVD-SiC. Joints with intentionally introduced porosity also failed out-of-plane until the joint modulus, which is reduced by the porosity, became less than about 1/3 of the CVD-SiC modulus. At that point in-plane shear failures were observed. However, these results notwithstanding, miniature torsion THG specimens can still be useful for identifying joint degradation following in-reactor radiation damage by observing either fracture mode changes or observable microstructural changes. The use of THG specimens for 
true joint shear strength measurements is problematic, however. The elastic and elastic-plastic damage models appear to be useful methods that can provide valuable insights into the THG fracture behavior.

\section{Acknowledgements}

This research was supported by Office of Fusion Energy Sciences, U.S. Department of Energy (DOE) under Contract DE-AC05-76RL01830. PNNL is a multi-program national laboratory operated by Battelle Memorial Institute for the US Department of Energy under DEAC06-76RLO 1830. The authors thank Prof. Jacques Lamon for helpful discussions. 


\section{References}

1. Katoh, Y., L.L. Snead, T. Cheng, C. Shih, W.D. Lewis, T. Koyanagi, T. Hinoki, C.H. Henager Jr, and M. Ferraris, J. Nucl. Mater., 448(1-3) (2014) 497-511. DOI:10.1016/j.jnucmat.2013.10.002.

2. Henager, J., Charles H. and R.J. Kurtz, J. Nucl. Mater., 417(1-3) (2011) 375-378. DOI:10.1016/j.jnucmat.2010.12.084.

3. Ferraris, M., M. Salvo, V. Casalegno, S. Han, Y. Katoh, H.C. Jung, T. Hinoki, and A. Kohyama, J. Nucl. Mater., 417(1-3) (2011) 379-82. DOI:10.1016/j.jnucmat.2010.12.160.

4. Colombo, P., B. Riccardi, A. Donato, and G. Scarinci, J. Nucl. Mater., 278(2) (2000) 127-135.

5. Colombo, P., V. Sglavo, E. Pippel, and J. Woltersdorf, Journal of Materials Science, 33(9) (1998) 2405-2412.

6. Jones, R.H. and C.H. Henager Jr, J. Nucl. Mater., 219 (1995) 55-62. DOI:10.1016/00223115(94)00390-4.

7. Ferraris, M., C. Badini, M. Montorsi, P. Appendino, and H.W. Scholz, J. Nucl. Mater., 212-1(pt B) (1994) 1613-1616. DOI:10.1016/0022-3115(94)91100-2.

8. Jung, H.-C., T. Hinoki, Y. Katoh, and A. Kohyama, J. Nucl. Mater., 417(1-3) (2011) 383-386. DOI:10.1016/j.jnucmat.2010.12.082.

9. Serizawa, H., C.A. Lewinsohn, and H. Murakawa. in 25th Annual Conference on Composites, Advanced Ceramics, Materials and Structures: B, January 21, 2001 - January 27, 2001. 2001. Cocoa Beach, FL, United states: American Ceramic Society.

10. Lewinsohn, C.A., M. Singh, T. Shibayama, T. Hinoki, M. Ando, Y. Katoh, and A. Kohyama, J. Nucl. Mater., 283-287 (2000) 1258-61.

11. Serizawa, H., C.A. Lewinsohn, and H. Murakawa, Mater. Trans., 43 (2002) 994-1000. DOI:10.2320/matertrans.43.994.

12. Serizawa, H., C.A. Lewinsohn, M. Singh, and H. Murakawa, Mater. Sci. Forum, 539-543(3) (2007) 2143-8. DOI:10.4028/http://www.scientific.net/MSF.539-543.2143. 
13. Lewinsohn, C.A., R.H. Jones, P. Colombo, and B. Riccardi, J. Nucl. Mater., 307-311(2 SUPPL) (2002) 1232-1236.

14. Salvo, M., P. Lemoine, M. Ferraris, and M. Montorsi, J. Am. Ceram. Soc., 80(1) (1997) 206-12.

15. Serizawa, H., D. Fujita, C.A. Lewinsohn, M. Singh, and H. Murakawa, J. Nucl. Mater., 367-370 B(SPEC. ISS.) (2007) 1223-1227.

16. Fang, N.J.J. and T.-W. Chou, J. Am. Ceram. Soc., 76(10) (1993) 2539-2548.

17. Dadras, P. and J.S. McDowell, Experimental Mechanics, 30(2) (1990) 184-189.

18. Li, M., R. Matsuyama, and M. Sakai, Carbon, 37(11) (1999) 1749-1757. DOI:10.1016/S00086223(99)00049-4.

19. Fujita, D., H. Serizawa, M. Singh, and H. Murakawa, Ceramic Engineering and Science Proceedings, 26 (2005) 417-424.

20. Ferraris, M., A. Ventrella, M. Salvo, Y. Katoh, and D. Gross, Int. J. Appl. Ceram. Technol., in press (2014). DOI:10.1111/ijac.12248.

21. Ferraris, M., A. Ventrella, M. Salvo, and D. Gross, Int. J. Appl. Ceram. Technol., 11(2) (2014) 394401. DOI:10.1111/ijac.12025.

22. Hinoki, T., Y. Katoh, L.L. Snead, H.-C. Jung, K. Ozawa, H. Katsui, Z.-H. Zhong, S. Kondo, Y.-H. Park, C. Shih, C.M. Parish, R.A. Meisner, and A. Hasegawa, Mater. Trans., 54(4) (2013) 472-476. DOI:10.2320/matertrans.MG201206.

23. Ferraris, M., M. Salvo, S. Rizzo, V. Casalegno, S. Han, A. Ventrella, T. Hinoki, and Y. Katoh, Int. J. Appl. Ceram. Technol., 9(4) (2012) 786-794. DOI:10.1111/j.1744-7402.2012.02775.x.

24. Ferraris, M., M. Salvo, V. Casalegno, M. Avalle, and A. Ventrella, Int. J. Appl. Ceram. Technol., 9(4) (2012) 795-807. DOI:10.1111/j.1744-7402.2011.02740.x.

25. C. H. Henager, J., R.J. Kurtz, A. Ventrella, and M. Ferraris, in Fusion Reactor Materials Program Semiannual Progress Reports, F. Wiffen, R. Godfrey, and B. Waddell, Editors. 2011, ORNL: Oak Ridge, TN. p. 51-56. 
26. Xu, B., Fracture Mechanisms and Failure Criteria of Adhesive Joints and Toughened Epoxy Adhesives, 2010, Queen Mary, University of London, University of London.

27. Broughton, W.R., L.E. Crocker, and J.M. Urquhart, Strength of Adhesive Joints: A Parametric Study. 2001, National Physical Laboratory: NPL Materials Centre, National Physical Laboratory, Teddington, Middlesex, TW11 0LW, UK. p. 41.

28. Snead, L.L., T. Nozawa, Y. Katoh, T.-S. Byun, S. Kondo, and D.A. Petti, J. Nucl. Mater., 371(1-3) (2007) 329-377.

29. Timoshenko, S.P. and J.N. Goodier, Theory of Elasticity. Third ed. Engineering Societies Monographs. 1970, New York: McGraw Hill.

30. Nguyen, B.N., B.J. Koeppel, S. Ahzi, M.A. Khaleel, and P. Singh, J. Am. Ceram. Soc., 89(4) (2006) 1358-1368. DOI:10.1111/j.1551-2916.2005.00874.x.

31. Lemaitre, J. and J.L. Chaboche, Journal de Mecanique Appliquee, 2(3) (1978) 317-65.

32. Maugin, G.A., The Thermomechanics of Plasticity and Fracture. 1992, Cambridge, UK: Cambridge University Press.

33. Renard, J., J.P. Favre, and T. Jeggy, Compos. Sci. Technol., 46(1) (1993) 29-37. DOI:10.1016/02663538(93)90078-U.

34. Tvergaard, V., Int. J. Fract., 31(3) (1986) 183-209. DOI:10.1007/BF00018927.

35. Nguyen, B.N., V. Kunc, J.H. Phelps, C.L. Tucker Iii, and S.K. Bapanapalli. in 23rd Technical Conference of the American Society for Composites 2008, September 9, 2008 - September 11, 2008. 2008. Memphis, TN, United states: DEStech Publications Inc.

36. Nguyen, B.N. and V. Kunc, Int. J. Damage Mech., 19(6) (2010) 691-725. DOI:10.1177/1056789509338319.

37. Lemaitre, J., in Continuum Damage Mechanics of Materials and Structures, O. Allix and F. Hild, Editors. 2002, Elsevier Science Ltd: Oxford, UK. p. 235-258.

38. Lemaître, J. and J.-L. Chaboche, Mécanique des Matériaux Solides. 1985, Paris, France: Dunod. 
39. Byun, T.S., N. Hashimoto, and K. Farrell, Acta Mater., 52(13) (2004) 3889-3899. DOI:10.1016/j.actamat.2004.05.003.

40. Nguyen, B.N., EMTA User’s Guide. 2010, Pacific Northwest National Laboratory: Richland, WA.

41. Deshpande, V.S. and A.G. Evans, Journal of the Mechanics and Physics of Solids, 56(10) (2008) 3077-3100. DOI:10.1016/j.jmps.2008.05.002.

42. Deshpande, V.S., E.A.N. Gamble, B.G. Compton, R.M. McMeeking, A.G. Evans, and F.W. Zok, J. Am. Ceram. Soc., 94(SUPPL. 1) (2011) S204-S214. DOI:10.1111/j.1551-2916.2011.04516.x.

43. Chen, C.K., Fatigue Fract. Eng. Mater. Struct., 27(1) (2004) 45-50. DOI:10.1111/j.14602695.2004.00718.x.

44. Ortiz, M. and A.E. Giannakopoulos, International Journal of Solids and Structures, 26(7) (1990) 705723. DOI:10.1016/0020-7683(90)90002-D.

45. Chao, L.-Y. and D.K. Shetty, J. Am. Ceram. Soc., 73(7) (1990) 1917-1921.

46. Nemeth, N.N., Int. J. Fract., 185(1-2) (2014) 97-114. DOI:10.1007/s10704-013-9906-4.

47. Fett, T., D. Munz, and G. Thun, J. Am. Ceram. Soc., 86(8) (2003) 1427-1429.

48. Suresh, S., C.F. Shih, A. Morrone, and N.P. O'Dowd, J. Am. Ceram. Soc., 73(5) (1990) 1257-1267.

49. Lamon, J., J. Am. Ceram. Soc., 73(8) (1990) 2204-2212.

50. Priddle, E.K., Journal of Strain Analysis, 4(2) (1969) 81-87. 


\section{LIST OF TABLES}

Table 1. Joint Porosity and Effective Modulus Calculations

Table 2. Joint Testing Summary ${ }^{* *}$

Table 3. Mechanical properties in shear of the CVD-SiC and joint materials assumed for the analysis.

Table 4. Parameters of the elastic-plastic models identified for 316SS and AV119.

${ }^{* *}$ Base refers to fracture of entire sample, Joint refers to fracture in plane in the joint region. Test efficiency refers to the number of inplane joint failures (Joint) compared to the total number of tests. 


\section{LIST OF FIGURES}

Figure 1. The miniature torsion specimen geometry used in this study in schematic form in (a) and an optical image in (b) with dimensions in mm from Ref. [1].

Figure 2. Miniature torsion half shown in (a) with 3.1-mm dimple to create annular joining area and shown in (b) is a cross-section of a joint created using a 2.3-mm dimpled half. This creates an annular joined area for reduced joined area testing as discussed in the text.

Figure 3. SEM images of polished $\mathrm{Ti}_{3} \mathrm{SiC}_{2}+\mathrm{SiC} / \mathrm{CVD}-\mathrm{SiC}$ joint cross-sections for each of the five joining pressures used to fabricate miniature torsion test specimens. Shown in (a) $5 \mathrm{MPa}$, (b) $10 \mathrm{MPa}$, (c) $20 \mathrm{MPa}$, (d) $30 \mathrm{MPa}$, and in (e) $40 \mathrm{MPa}$ joining pressure. The corresponding porosity and effective modulus data are shown in Fig. 4.

Figure 4. Calculated effective joint modulus as a function of applied joining pressure. The modulus defect is due to porosity, which is a function of joining pressure.

Figure 5. Joint strength data for PNNL $\mathrm{Ti}_{3} \mathrm{SiC}_{2}+\mathrm{SiC} / \mathrm{CVD}-\mathrm{SiC}$ joints (see Fig. 3) combining ORNL unirradiated dataset with POLITO data as a function of joining pressure or inner diameter for reduced joining area joints. All joints processed at $1698 \mathrm{~K}\left(1425{ }^{\circ} \mathrm{C}\right)$ for $2 \mathrm{~h}$ from the same tape cast lot with the exception of three $5 \mathrm{MPa}$ joints processed an additional $2 \mathrm{~h}$ at $1823 \mathrm{~K}$ $\left(1550{ }^{\circ} \mathrm{C}\right)$. There is a transition from base to in-plane joint failures between 10 and $5 \mathrm{MPa}$ joining pressure.

Figure 6. Optical images of fractured $\mathrm{Ti}_{3} \mathrm{SiC}_{2}+\mathrm{SiC} / \mathrm{CVD}-\mathrm{SiC}$ torsion specimens where the fracture is in the base material. Shown in (a) is a full-bonded joint and in (b) is a reduced area joint. Both joints are produced using 30 to $40 \mathrm{MPa}$ of joining pressure that creates a high strength joint.

Figure 7. Torsion fracture surfaces of $5 \mathrm{MPa} \mathrm{Ti}_{3} \mathrm{SiC}_{2}+\mathrm{SiC} / \mathrm{CVD}-\mathrm{SiC}$ joining pressure samples. Shown in (a) is an SEM image after testing in POLITO showing the in-plane failure mode with joining material residue on surface of tested miniature specimen. In (b) is an optical image of a sample tested at PNNL with similar results. 
Figure 8. Stress-strain responses considered for shear loading in an elastic damage model for CVD-SiC and different porosities of Ti3SiC2+SiC joint material, including a brittle epoxy. See Table 3 for model parameters.

Figure 9. (a) 3D finite element model for the torsion joint specimen with assigned material behaviors. The torsion loads are shared between the CVD-SiC that is either elastic or elasticdamage and the thin joint region represented as $10-\mu \mathrm{m}$ thick and modeled as elastic-damage material. For 316SS and AV119 epoxy materials these regions are modeled using the elasticplastic damage method. (b) Contour of the equivalent Mises stresses for Case 1 for an applied rotation angle before the onset of cracking for the entire THG model.

Figure 10. (a) Damage accumulation at fracture initiation in the specimen with $\mathrm{Ti}_{3} \mathrm{SiC}_{2}+\mathrm{SiC}$ (case 1) joint, and (b) a snapshot showing fracture initiation at the neck and in the CVD-SiC joined materials. Shown in (c) is the predicted advanced state of damage and fracture showing failure of the joined CVD-SiC materials occurring in the base material due to damage accumulation within the CVD-SiC. This material combination shows fracture initiation and failure within the CVD-SiC before it occurs in the joint region.

Figure 11. Contours of (a) shear stress $\tau_{r t}$, (b) shear stress $\tau_{t z}$, (c) equivalent Von Mises stress, and (d) strain energy density causing damage and fracture of Case 1 torsion joint specimen illustrated in Figs. 10b and 10c.

Figure 12. (a) Damage accumulation at fracture initiation in the specimen with the most porous $\mathrm{Ti}_{3} \mathrm{SiC}_{2}+\mathrm{SiC}$ (case 5) joint made using $5 \mathrm{MPa}$ of joining pressure. Shown in (b) is a snapshot showing fracture initiation along the joint line. Shown in (c) is the predicted advanced state of damage showing failure of the porous joint material due to damage accumulation within the joint. This material combination shows fracture initiation and failure within the joint region.

Figure 13. Predicted fracture patterns (red regions) using an elastic damage model for the THG joint specimens made of different joint materials with mechanical properties listed in Table 3. Cases 1, 2, and 3 fail within the CVD-SiC base material (out-of-plane), while case 4 sometimes fails within the joint (see Fig. 5). Case 5 always fails in the joint region. Case 6 shows results 
from the brittle epoxy simulation, which also fails within the joint without exception. See Fig. 11 for stress distributions for Case 1.

Figure 14. Predicted and experimental stress-strain responses for (a) 316SS [39] and (b) AV119 epoxy [27] (see Table 4 for model parameters).

Figure 15. Predicted fracture patterns using an elastic-plastic damage model for the AV119 adhesive epoxy and for 316SS. Shown in (a) is the predicted fracture for CVD-SiC joined with AV119 where the epoxy is elastic-plastic and the CVD-SiC is elastic. Shown in (b) is the case for both materials obeying the elastic-plastic damage model for 316SS joined with AV119 epoxy. In all cases the failure occurs within the epoxy joint.

Figure 16. Graph showing the predicted maximum shear stresses at fracture in (a) for all damage model simulations compared to experimental data. The numbers in red refer to the ratio of the modulus of the joint material to that of CVD-SiC. Shown in (b) is the predicted evolution of the maximum in-plane shear stresses with applied rotation angle for the elastic-plastic AV119 cases from Fig. 15. 
Tables

Table 1. Joint Porosity and Effective Modulus Calculations

\begin{tabular}{|cccc|}
\hline $\begin{array}{c}\text { Joining Pressure } \\
\text { (MPa) }\end{array}$ & $\begin{array}{c}\text { Measured Joint Area } \\
(\mathbf{\%})\end{array}$ & $\begin{array}{c}\text { Total Porosity } \\
(\mathbf{\%})\end{array}$ & $\begin{array}{c}\text { Effective Modulus } \\
\text { (GPa) }\end{array}$ \\
\hline 40 & - & 0 & 340 \\
30 & 99 & 3 & 308 \\
20 & 99 & 9 & 248 \\
10 & 99 & 24 & 146 \\
5 & 99 & 30 & 116 \\
\hline
\end{tabular}


Table 2. Joint Testing Summary ${ }^{\dagger \dagger}$

\begin{tabular}{|c|c|c|c|c|}
\hline Joint Type & $\begin{array}{l}\text { Pressure } \\
\text { (MPa) }\end{array}$ & Failure Mode & $\begin{array}{l}\text { Test Efficiency } \\
\text { (Joint/Total) }\end{array}$ & $\begin{array}{c}\text { Shear } \\
\text { Strength } \\
\text { (MPa) }\end{array}$ \\
\hline Full Bonded & 40 & Base & 0/18 (POLITO) & $\sim 80$ \\
\hline Full Bonded & 40 & Base & 0/6 (ORNL) & $117 \pm 10$ \\
\hline Full Bonded & 30 & Base & 0/3 (POLITO) & $83 \pm 16$ \\
\hline Full Bonded & 20 & Base & 0/3 (POLITO) & $77 \pm 5$ \\
\hline Full Bonded & 10 & Base, Joint & 2/3 (POLITO) & $\begin{array}{c}49 \pm 21(35 \pm \\
10)\end{array}$ \\
\hline Full Bonded & 5 & Joint & 6/6 (POLITO) & $(37 \pm 16)$ \\
\hline $\begin{array}{c}\text { Reduced (2.3 } \\
\text { mm) })^{\S \S}\end{array}$ & 40 & Base & 0/3 (POLITO) & $70 \pm 7$ \\
\hline Reduced (3.1 mm) & 40 & Base & 0/2 (POLITO) & $89 \pm 19$ \\
\hline
\end{tabular}

${ }^{+\dagger}$ Base refers to fracture of entire sample, Joint refers to fracture in plane in the joint region. Test efficiency refers to the number of inplane joint failures (Joint) compared to the total number of tests.

\# Numbers in parentheses are the true shear strength for in-plane joint failures.

$\S \S$ Numbers refer to inner diameter. 
Table 3. Mechanical properties in shear of the CVD-SiC and joint materials assumed for the analysis.

\begin{tabular}{|c|c|c|c|c|c|c|}
\hline Material & $\begin{array}{c}\text { Case } \\
\text { Study } \\
\text { No. }\end{array}$ & $\begin{array}{c}\text { Shear } \\
\text { Modulus } \\
\text { (GPa) }\end{array}$ & $\begin{array}{c}\text { Poisson } \\
\text { Ratio }\end{array}$ & $\begin{array}{c}\text { Shear } \\
\text { Strength } \\
\text { (MPa) }\end{array}$ & $\begin{array}{c}\text { Failure } \\
\text { Strain in } \\
\text { shear }\end{array}$ & $\begin{array}{c}\text { Damage } \\
\text { Variable } \\
\text { Critical } \\
\text { Value }\end{array}$ \\
\hline CVD-SiC & - & 192 & 0.2 & 184 & $1.2 \times 10^{-3}$ & 0.2 \\
\hline $\begin{array}{c}\mathrm{Ti}_{3} \mathrm{SiC}_{2}+\mathrm{SiC} \\
(0 \% \text { porosity })\end{array}$ & 1 & 158 & 0.2 & 304 & $2.4 \times 10^{-3}$ & 0.2 \\
\hline $\begin{array}{c}\mathrm{Ti}_{3} \mathrm{SiC}_{2}+\mathrm{SiC} \\
\text { (3\% porosity) }\end{array}$ & 2 & 143 & 0.2 & 274 & $2.4 \times 10^{-3}$ & 0.2 \\
\hline $\begin{array}{c}\mathrm{Ti}_{3} \mathrm{SiC}_{2}+\mathrm{SiC} \\
\text { (9\% porosity) }\end{array}$ & 3 & 115 & 0.2 & 220 & $2.4 \times 10^{-3}$ & 0.2 \\
\hline $\begin{array}{c}\mathrm{Ti}_{3} \mathrm{SiC}_{2}+\mathrm{SiC} \\
\text { (24\% porosity) }\end{array}$ & 4 & 68 & 0.2 & 130 & $2.4 \times 10^{-3}$ & 0.2 \\
\hline $\begin{array}{c}\mathrm{Ti}_{3} \mathrm{SiC}_{2}+\mathrm{SiC} \\
\text { (30\% porosity) }\end{array}$ & 5 & 54 & 0.2 & 103 & $2.4 \times 10^{-3}$ & 0.2 \\
\hline Epoxy (Brittle) & 6 & 3.8 & 0.3 & 47 & $2.0 \times 10^{-2}$ & 0.4 \\
\hline
\end{tabular}


Table 4. Parameters of the elastic-plastic models identified for $316 S$ S and AV119.

\begin{tabular}{|c|c|c|c|c|c|c|c|}
\hline Materials & E (MPa) & $\sigma_{0}$ (MPa) & $v$ & $n$ & $\bar{\varepsilon}_{\mathrm{p}}^{\mathrm{D}}$ & $\bar{\varepsilon}_{\mathrm{p}}^{\mathrm{R}}$ & $D_{\mathrm{c}}$ \\
\hline 316SS & 193000 & 150 & 0.3 & 4.3 & 0.02 & 0.42 & 0.7 \\
AV119 & 3200 & 110 & 0.34 & 3 & 0 & 0.01 & 0.45 \\
\hline
\end{tabular}




\section{Figures}
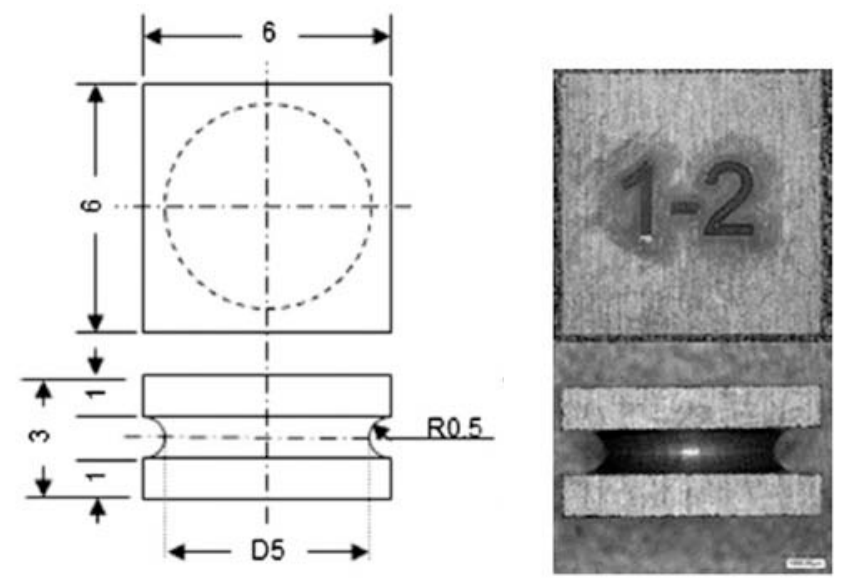

Type 6SQ-5D

(a)

(b)

Figure 1. The miniature torsion specimen geometry used in this study in schematic form in (a) and an optical image in (b) with dimensions in mm from Ref. [1]. 


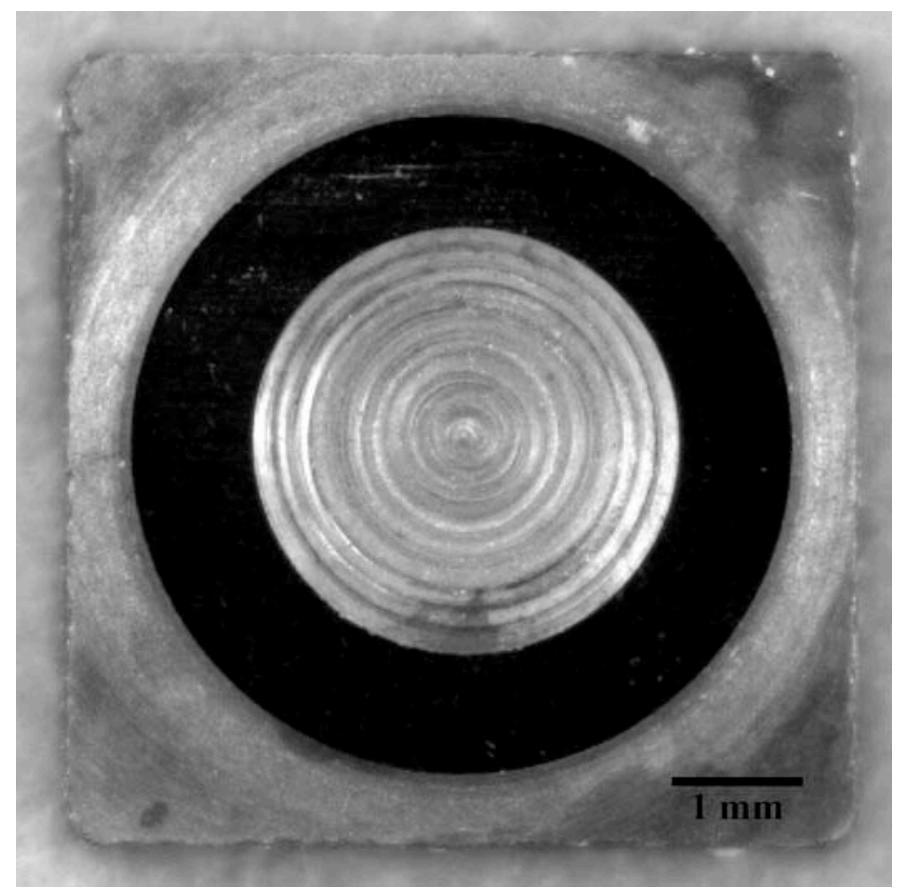

(a)

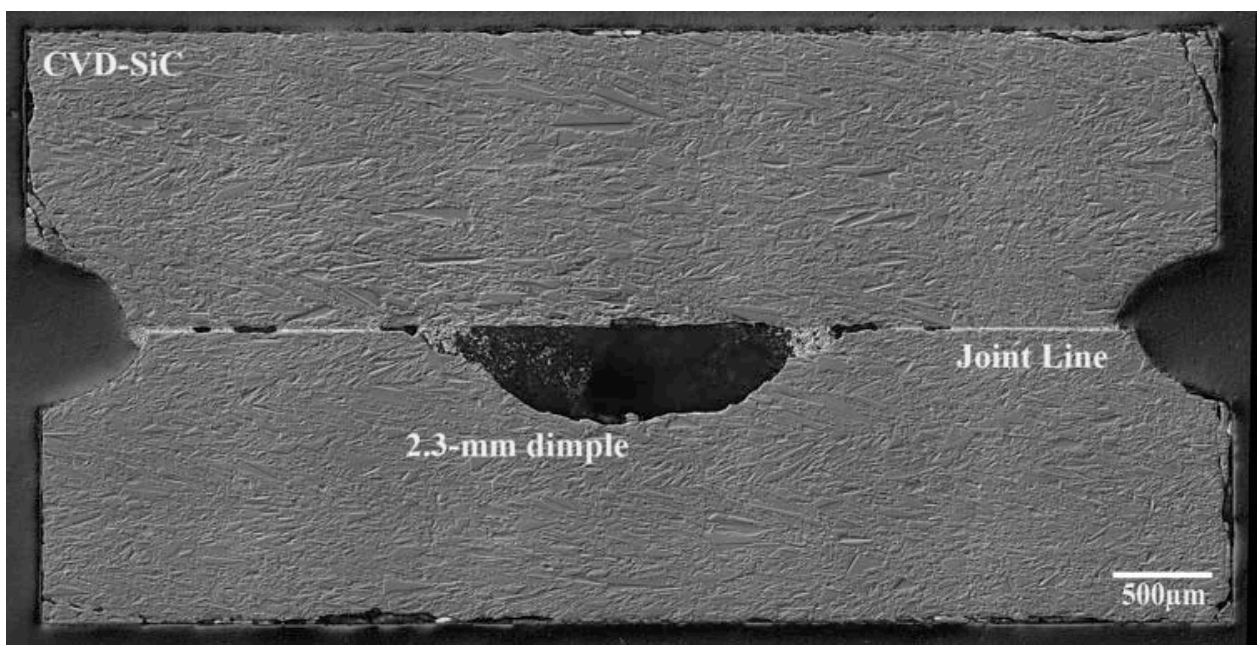

(b) 
Figure 2. Miniature torsion half shown in (a) with 3.1-mm dimple to create annular joining area and shown in (b) is a cross-section of a joint created using a 2.3-mm dimpled half. This creates an annular joined area for reduced joined area testing as discussed in the text.

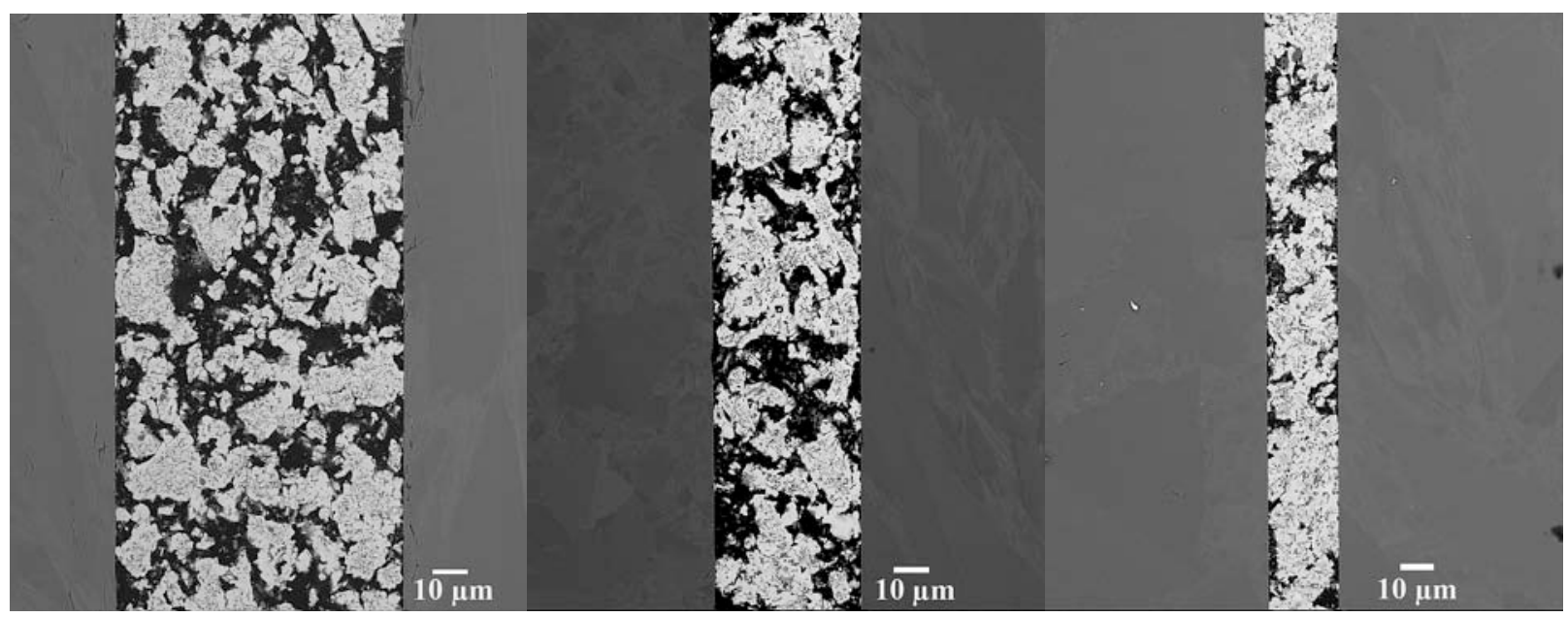

(a)

(b)

(c)

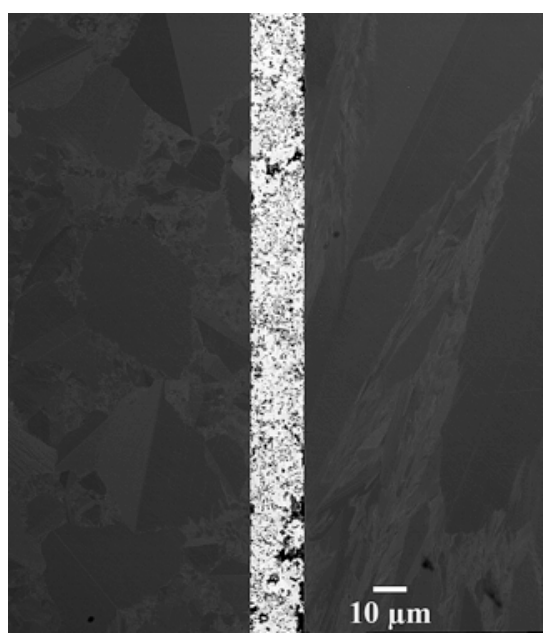

(d)

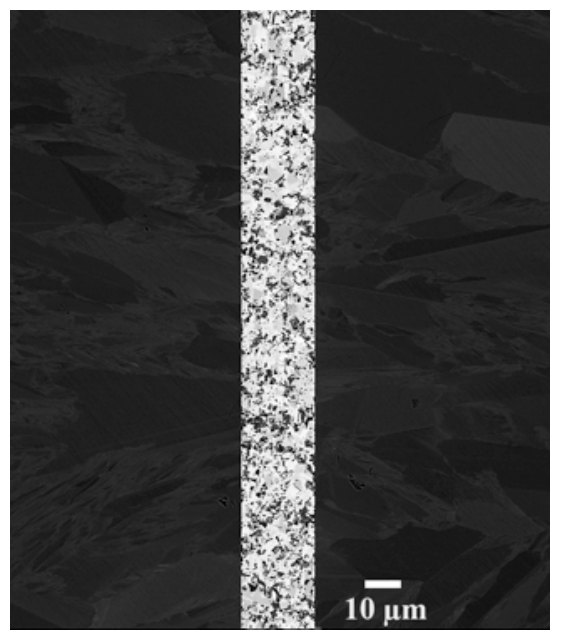

(e)

Figure 3. SEM images of polished $\mathrm{Ti}_{3} \mathrm{SiC}_{2}+\mathrm{SiC} / \mathrm{CVD}$-SiC joint cross-sections for each of the five joining pressures used to fabricate miniature torsion test specimens. Shown in (a) $5 \mathrm{MPa}$, (b) 
$10 \mathrm{MPa}$, (c) $20 \mathrm{MPa}$, (d) $30 \mathrm{MPa}$, and in (e) $40 \mathrm{MPa}$ joining pressure. The corresponding porosity and effective modulus data are shown in Fig. 4. 


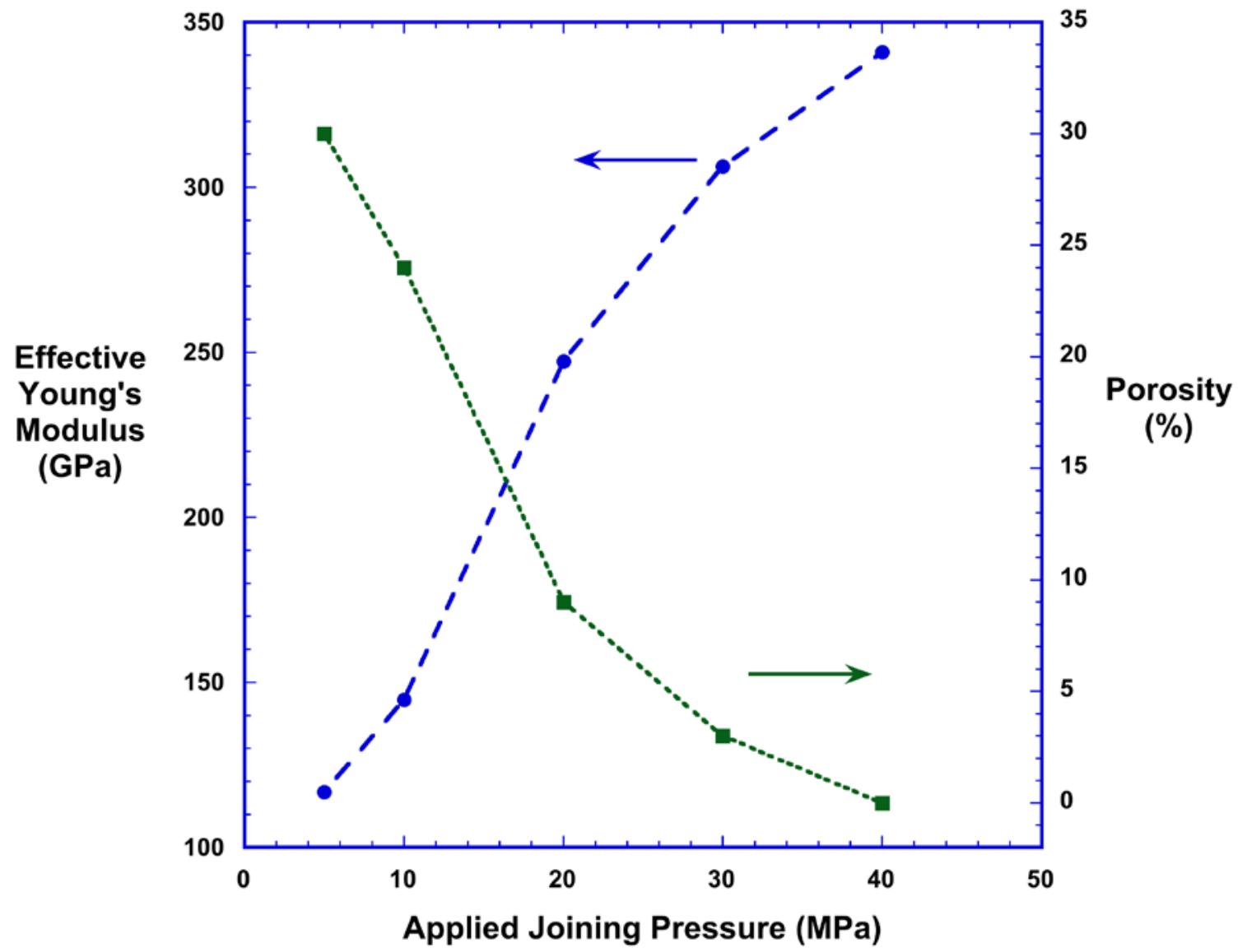

Figure 4. Calculated effective joint modulus as a function of applied joining pressure. The modulus defect is due to porosity, which is a function of joining pressure. 


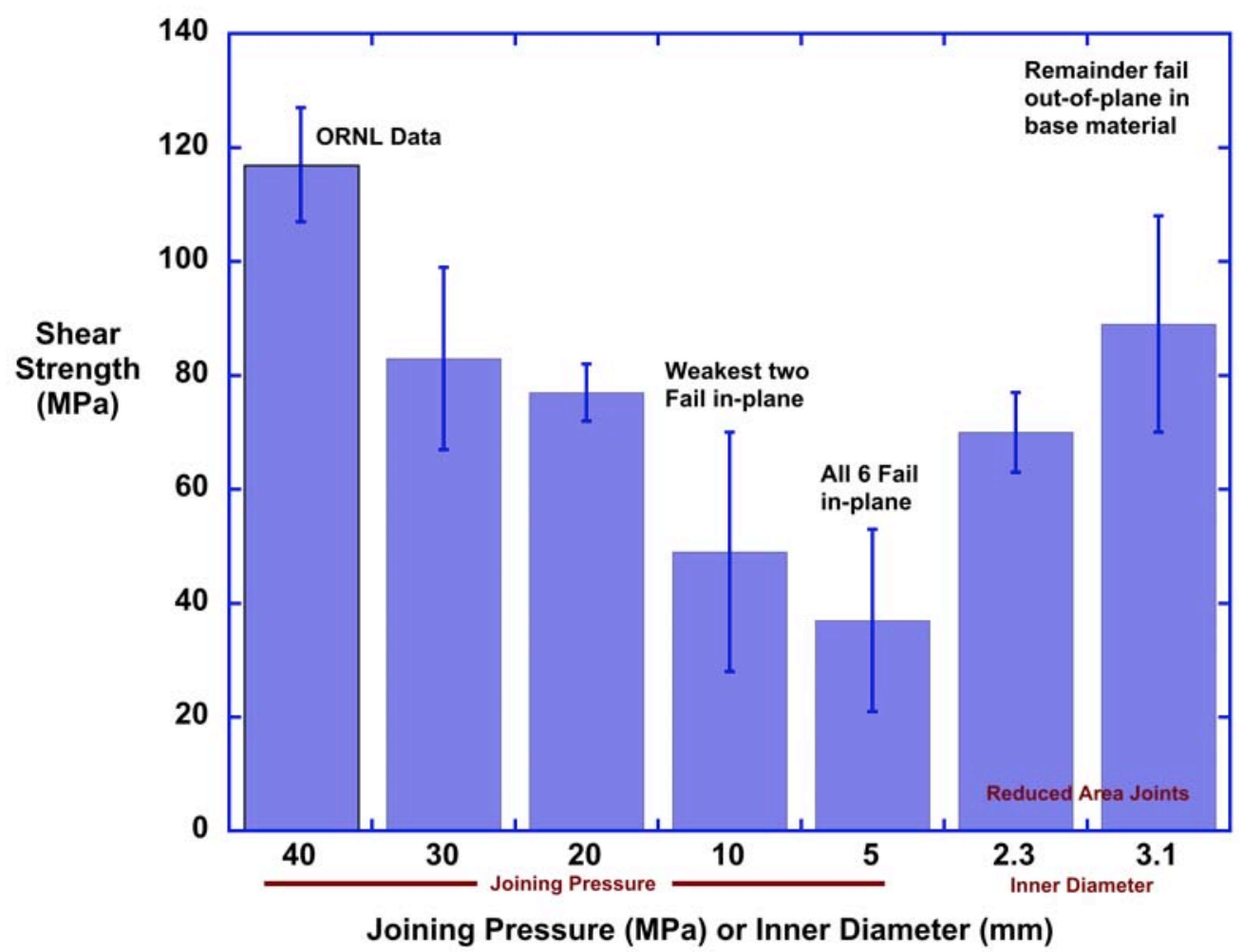

Figure 5. Joint strength data for PNNL $\mathrm{Ti}_{3} \mathrm{SiC}_{2}+\mathrm{SiC} / \mathrm{CVD}-\mathrm{SiC}$ joints (see Fig. 3) combining ORNL unirradiated dataset with POLITO data as a function of joining pressure or inner diameter for reduced joining area joints. All joints processed at $1698 \mathrm{~K}\left(1425{ }^{\circ} \mathrm{C}\right)$ for $2 \mathrm{~h}$ from the same tape cast lot with the exception of three $5 \mathrm{MPa}$ joints processed an additional $2 \mathrm{~h}$ at $1823 \mathrm{~K}$ $\left(1550{ }^{\circ} \mathrm{C}\right)$. There is a transition from base to in-plane joint failures between 10 and $5 \mathrm{MPa}$ joining pressure. 


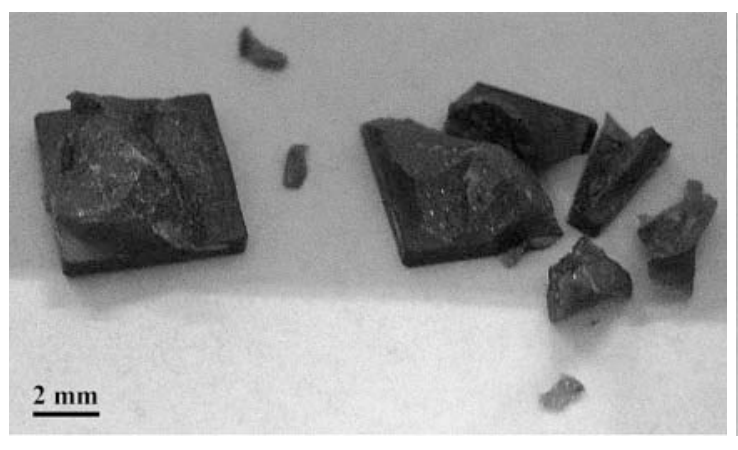

(a)

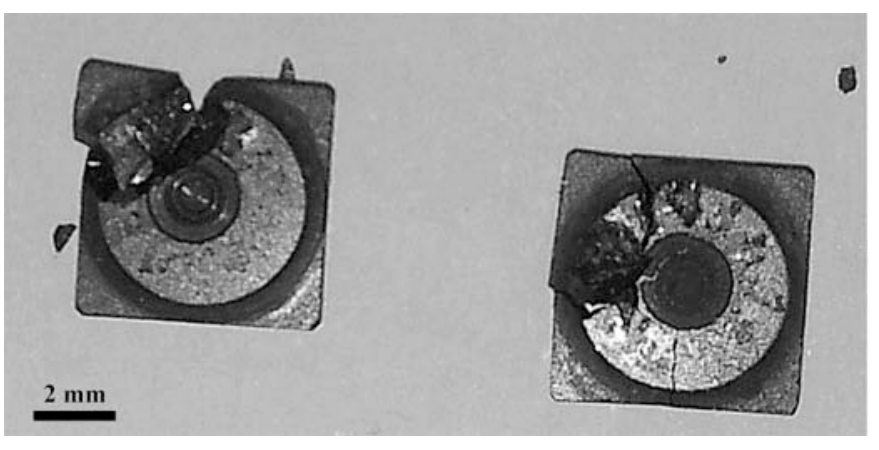

(b)

Figure 6. Optical images of fractured $\mathrm{Ti}_{3} \mathrm{SiC}_{2}+\mathrm{SiC} / \mathrm{CVD}$-SiC torsion specimens where the fracture is in the base material. Shown in (a) is a full-bonded joint and in (b) is a reduced area joint. Both joints are produced using 30 to $40 \mathrm{MPa}$ of joining pressure that creates a high strength joint. 


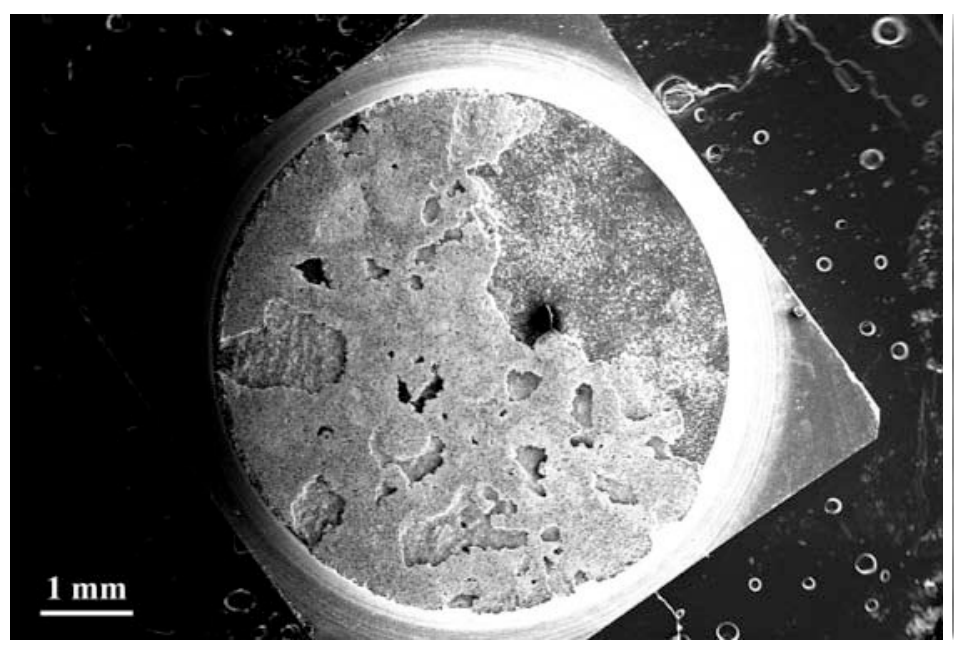

(a)

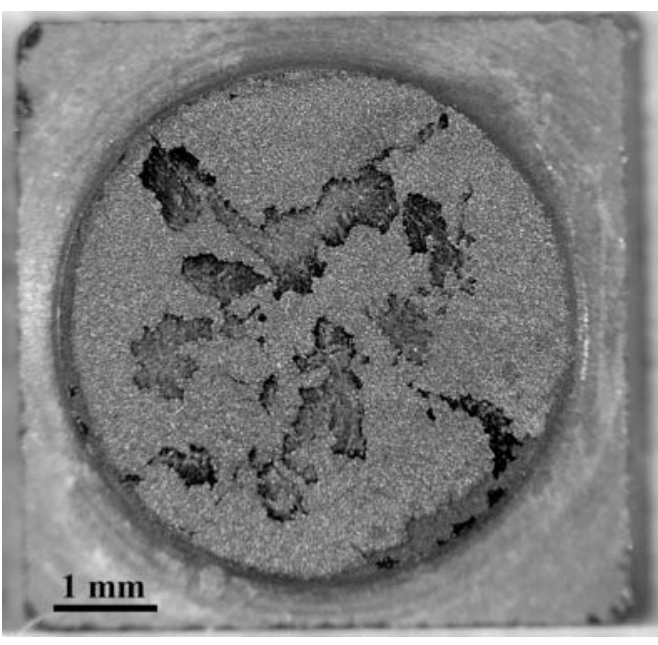

(b)

Figure 7. Torsion fracture surfaces of $5 \mathrm{MPa} \mathrm{Ti}_{3} \mathrm{SiC}_{2}+\mathrm{SiC} / \mathrm{CVD}-\mathrm{SiC}$ joining pressure samples. Shown in (a) is an SEM image after testing in POLITO showing the in-plane failure mode with joining material residue on surface of tested miniature specimen. In (b) is an optical image of a sample tested at PNNL with similar results. 


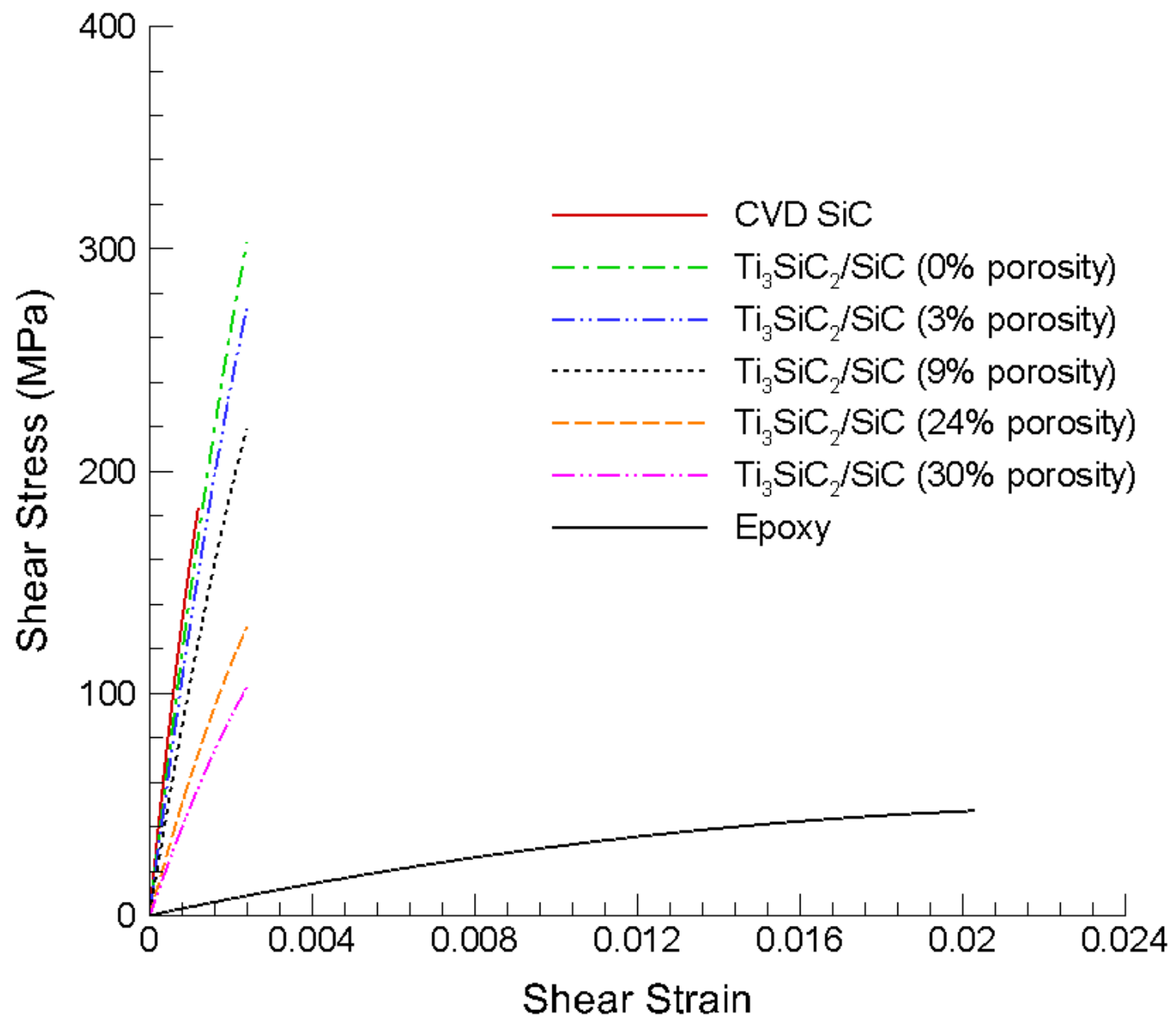

Figure 8. Stress-strain responses considered for shear loading in an elastic damage model for CVD-SiC and different porosities of $\mathrm{Ti}_{3} \mathrm{SiC}_{2}+\mathrm{SiC}$ joint material, including a brittle epoxy. See Table 3 for model parameters. 


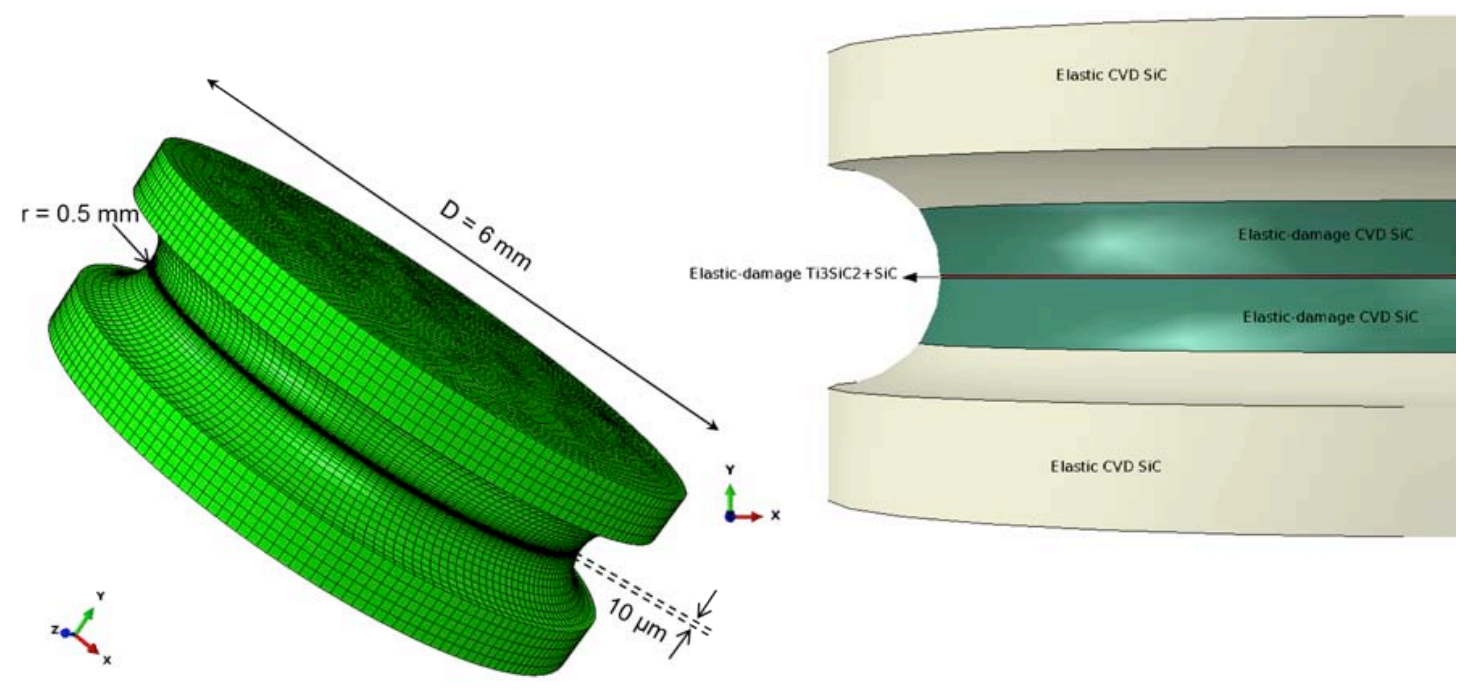

(a)

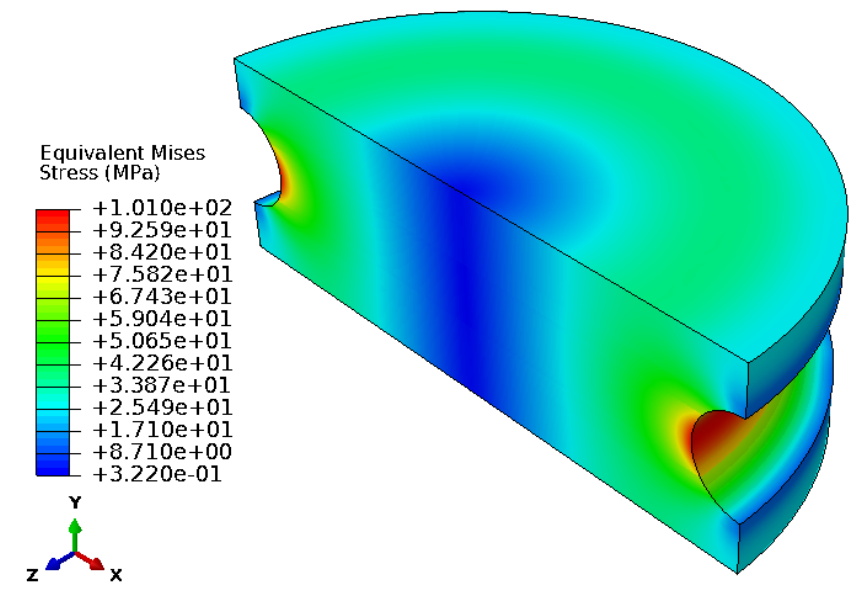

(b)

Figure 9. (a) 3D finite element model for the torsion joint specimen with assigned material behaviors. The torsion loads are shared between the CVD-SiC that is either elastic or elasticdamage and the thin joint region represented as $10-\mu \mathrm{m}$ thick and modeled as elastic-damage material. For 316SS and AV119 epoxy materials these regions are modeled using the elasticplastic damage method. (b) Contour of the equivalent Mises stresses for Case 1 for an applied rotation angle before the onset of cracking for the entire THG model. 


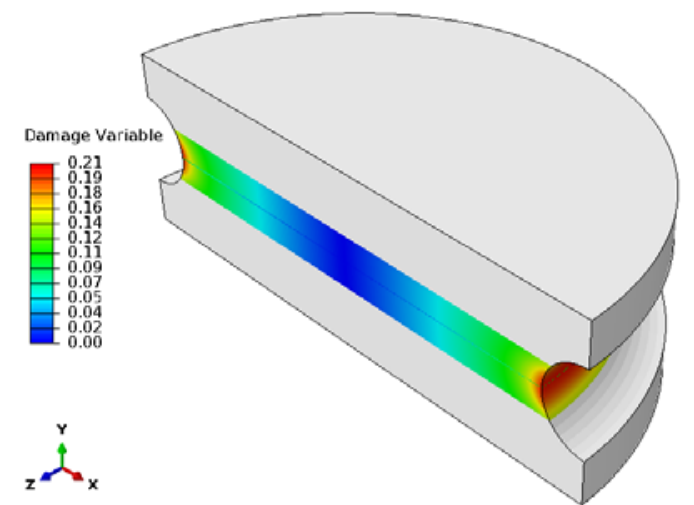

(a)

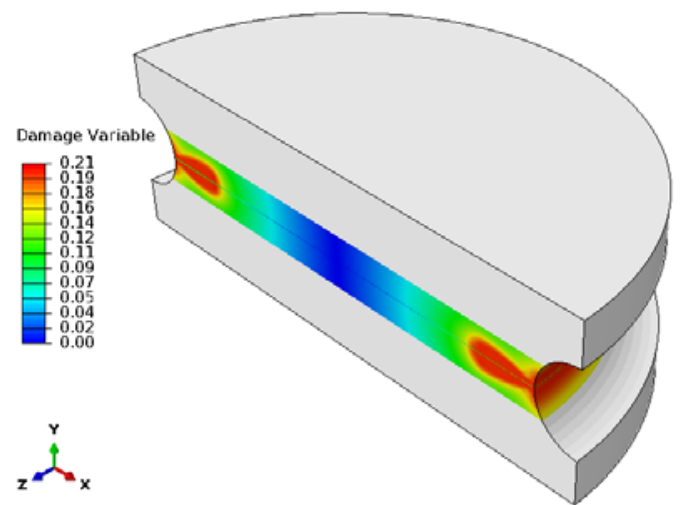

(b)

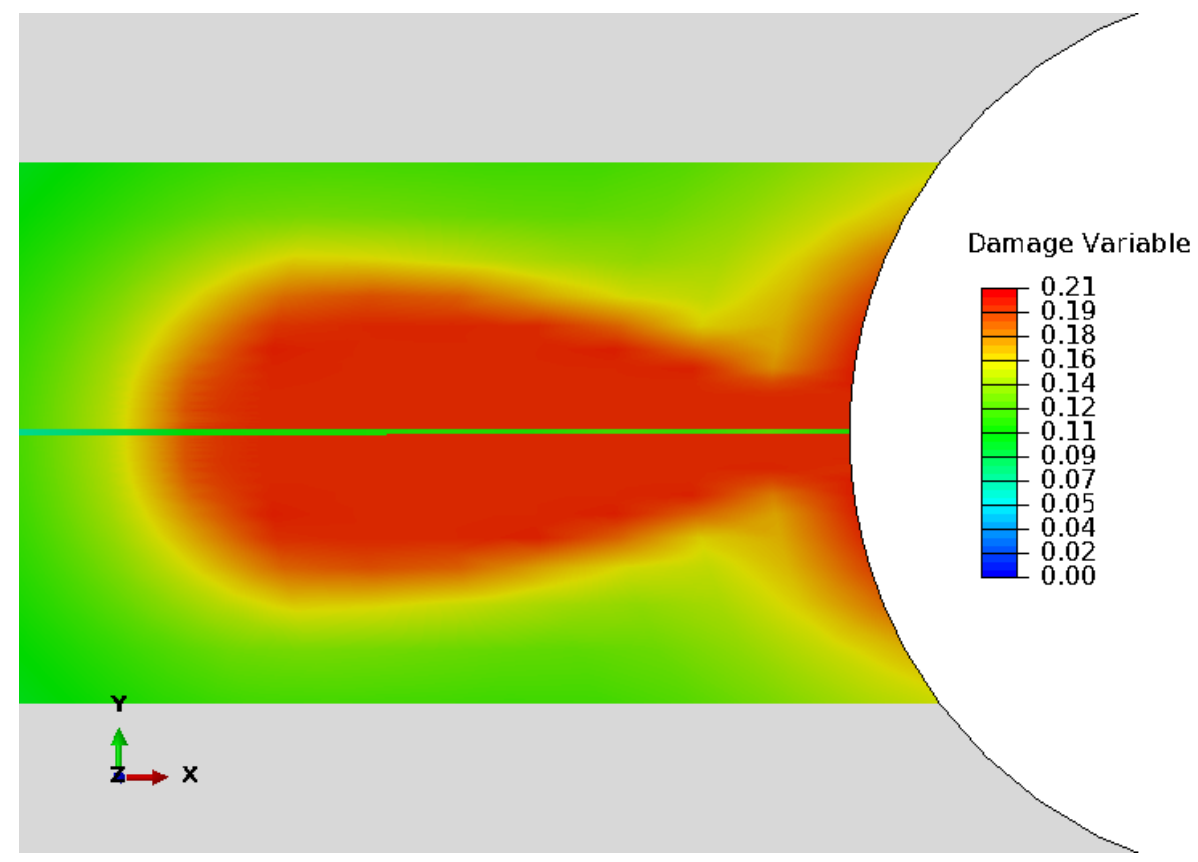

(c)

Figure 10. (a) Damage accumulation at fracture initiation in the specimen with $\mathrm{Ti}_{3} \mathrm{SiC}_{2}+\mathrm{SiC}$ (case 1) joint, and (b) a snapshot showing fracture initiation at the neck and in the CVD-SiC joined materials. Shown in (c) is the predicted advanced state of damage and fracture showing failure of the joined CVD-SiC materials occurring in the base material due to damage accumulation within the CVD-SiC. This material combination shows fracture initiation and failure within the CVD-SiC before it occurs in the joint region. 


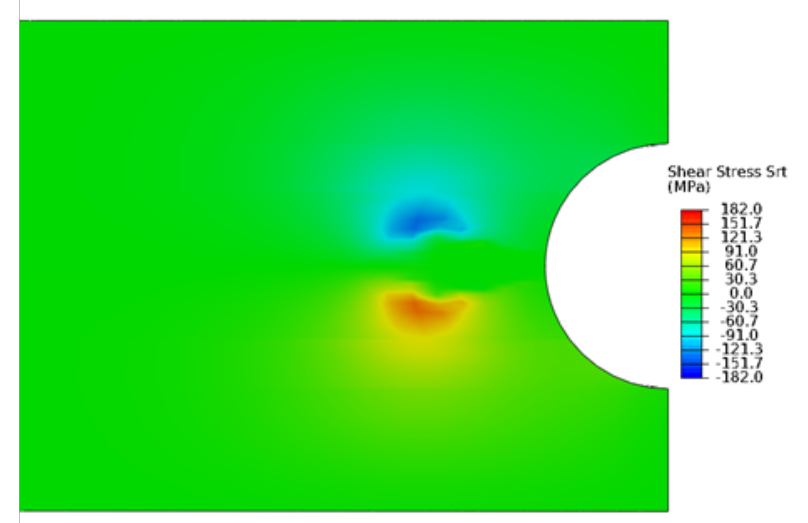

(a)

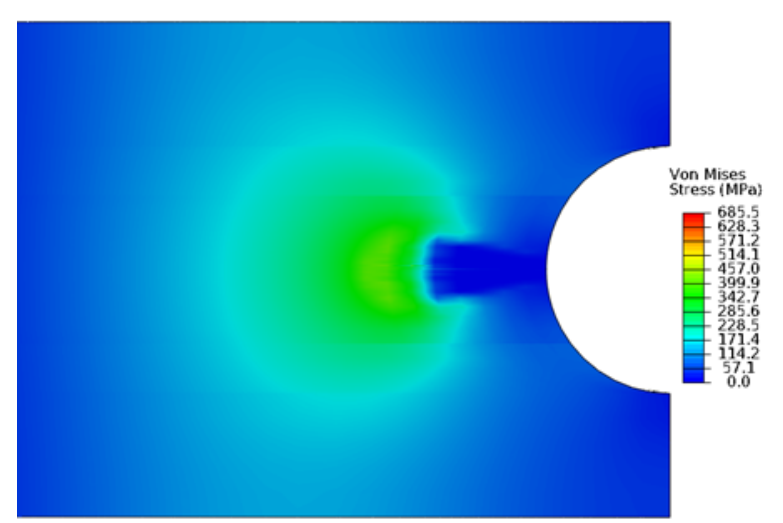

(c)

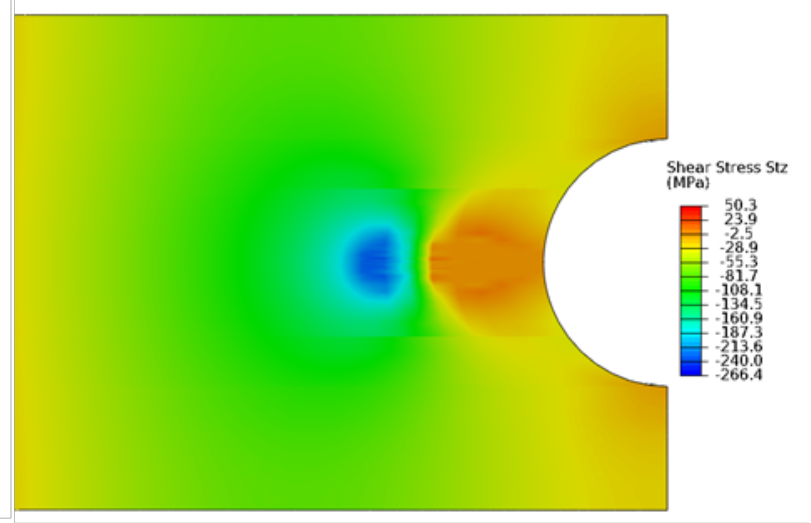

(b)

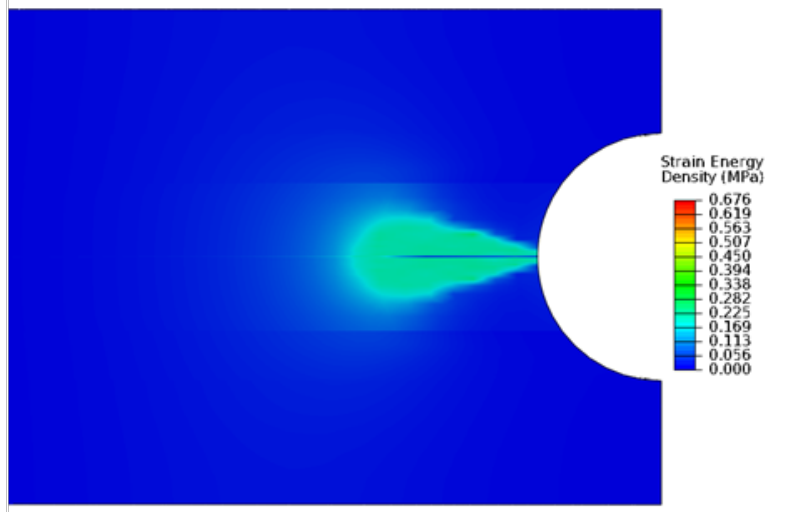

(d)

Figure 11. Contours of (a) shear stress $\tau_{r t}$, (b) shear stress $\tau_{t z}$, (c) equivalent Von Mises stress, and (d) strain energy density causing damage and fracture of Case 1 torsion joint specimen illustrated in Figs. 10b and 10c. 


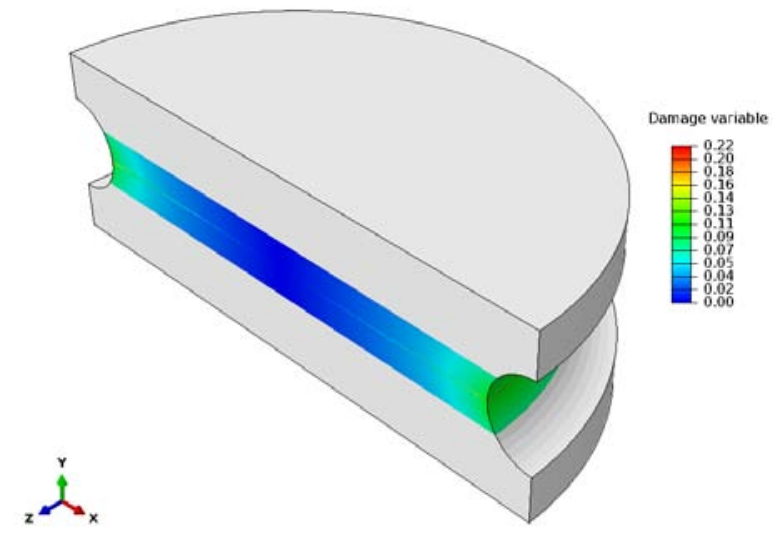

(a)

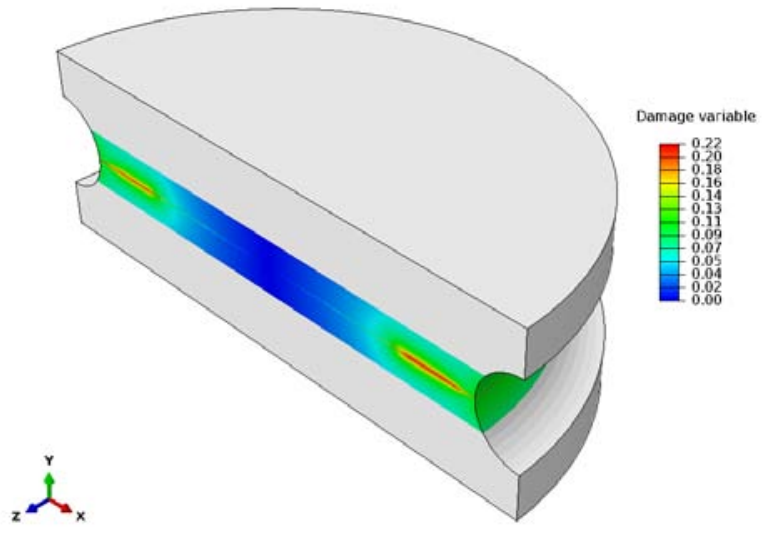

(b)

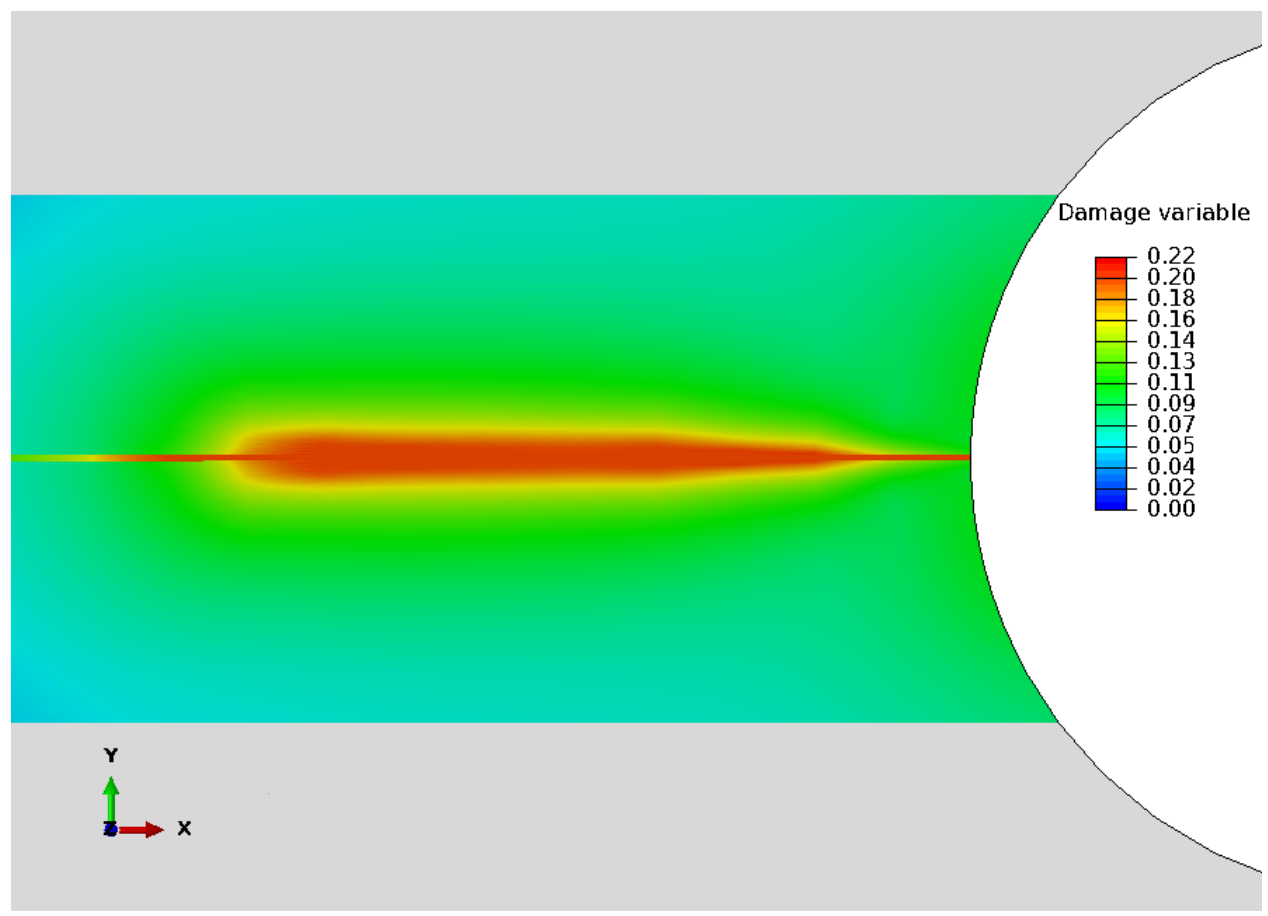

(c)

Figure 12. (a) Damage accumulation at fracture initiation in the specimen with the most porous $\mathrm{Ti}_{3} \mathrm{SiC}_{2}+\mathrm{SiC}$ (case 5) joint made using $5 \mathrm{MPa}$ of joining pressure. Shown in (b) is a snapshot showing fracture initiation along the joint line. Shown in (c) is the predicted advanced state of damage showing failure of the porous joint material due to damage accumulation within the joint. This material combination shows fracture initiation and failure within the joint region. 

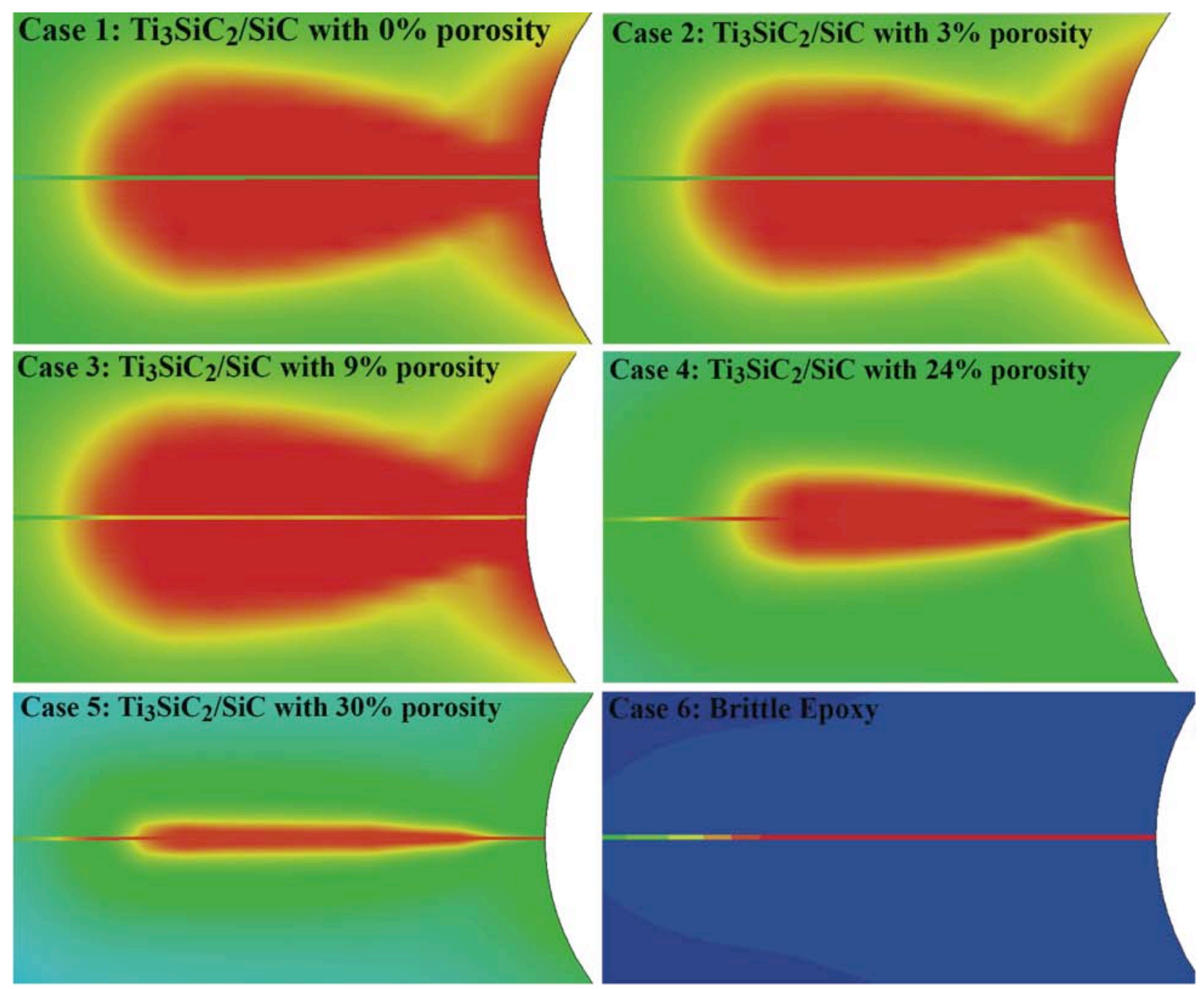

Figure 13. Predicted fracture patterns (red regions) using an elastic damage model for the THG joint specimens made of different joint materials with mechanical properties listed in Table 3.

Cases 1, 2, and 3 fail within the CVD-SiC base material (out-of-plane), while case 4 sometimes fails within the joint (see Fig. 5). Case 5 always fails in the joint region. Case 6 shows results from the brittle epoxy simulation, which also fails within the joint without exception. See Fig. 11 for stress distributions for Case 1. 


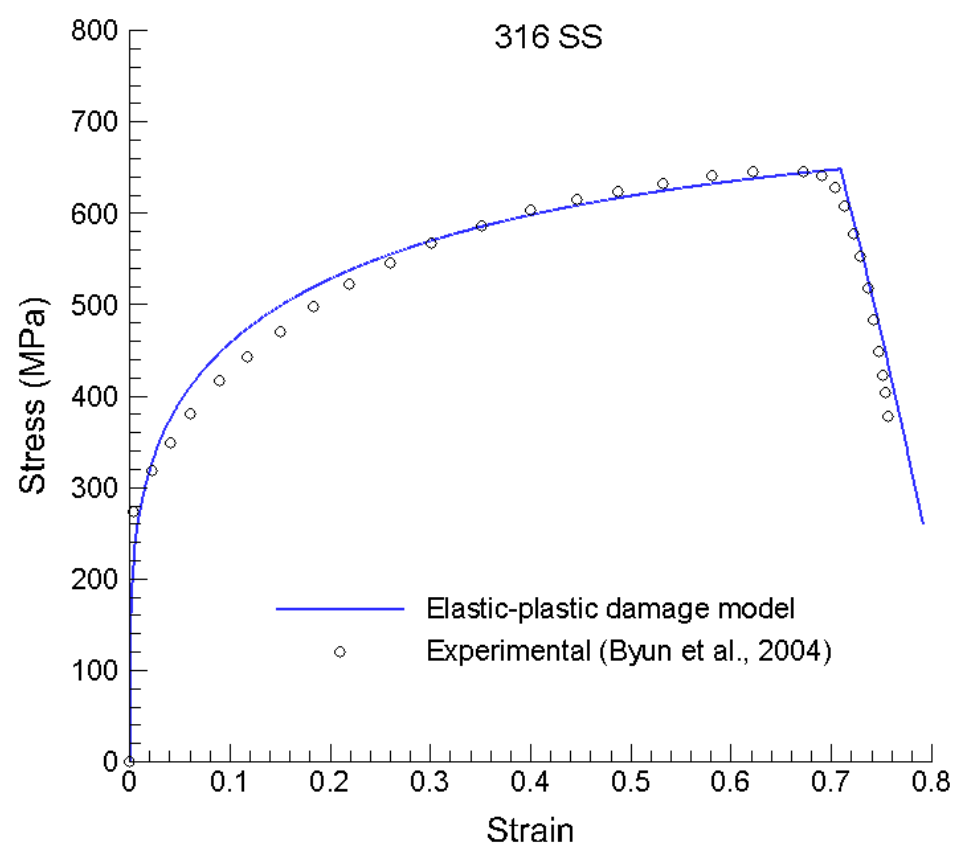

(a)

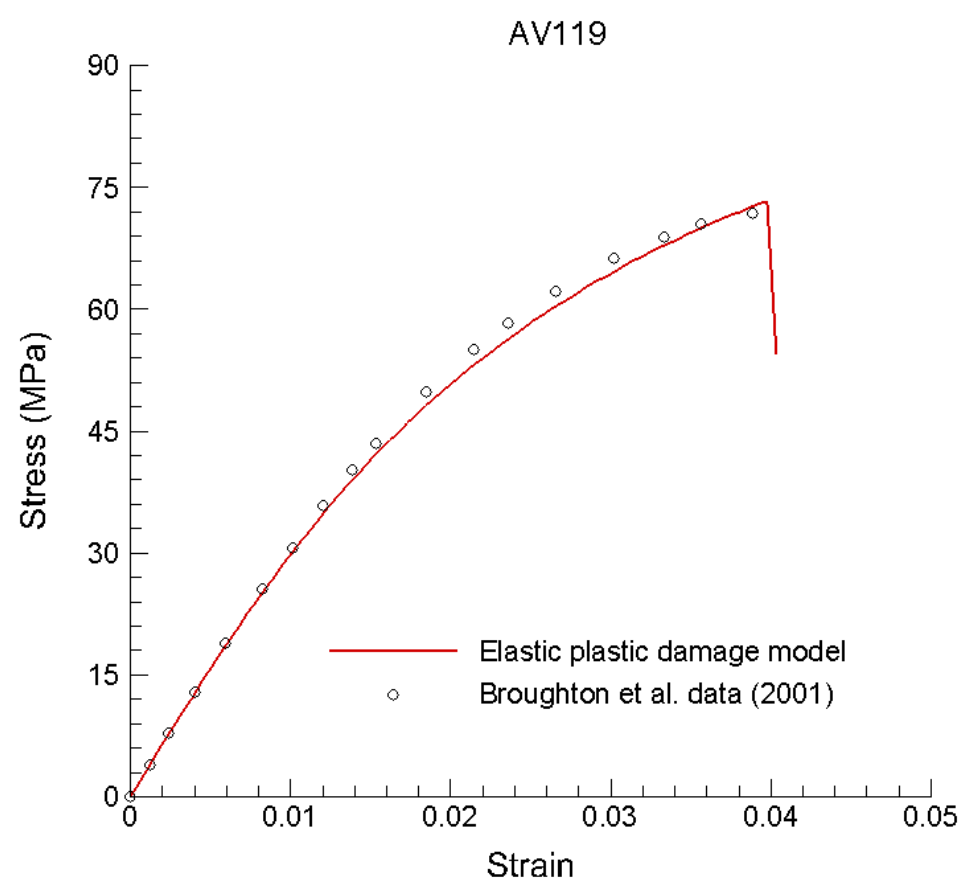

(b) 
Figure 14. Predicted and experimental stress-strain responses for (a) 316SS [39] and (b) AV119 epoxy [27] (see Table 4 for model parameters). 


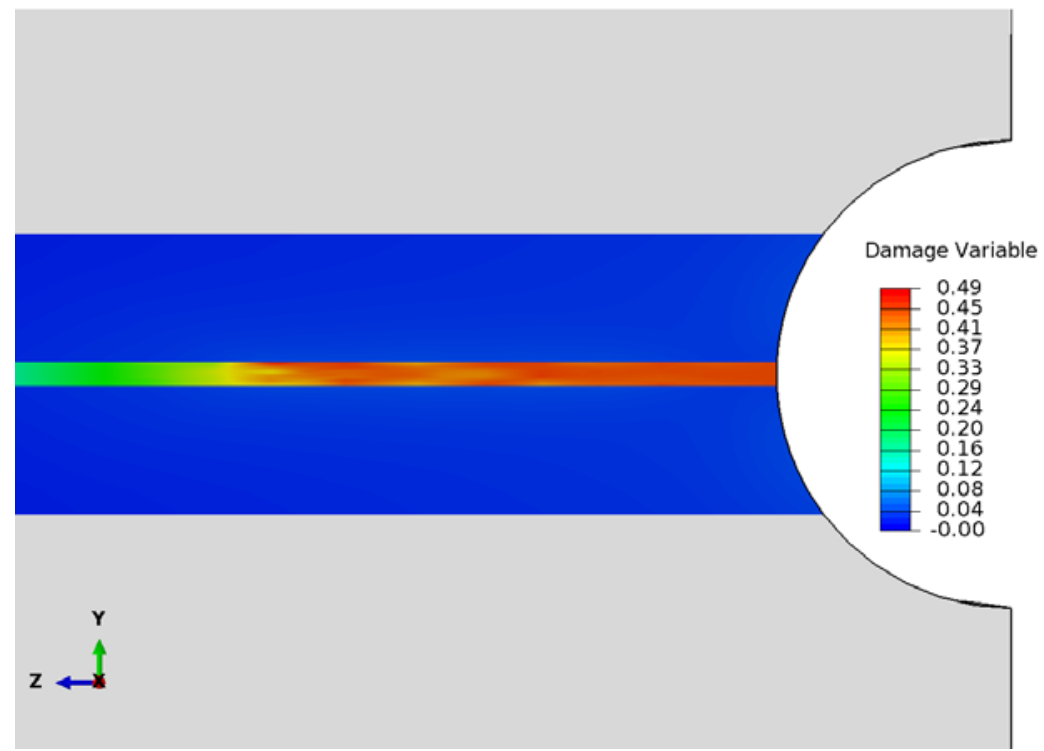

(a)

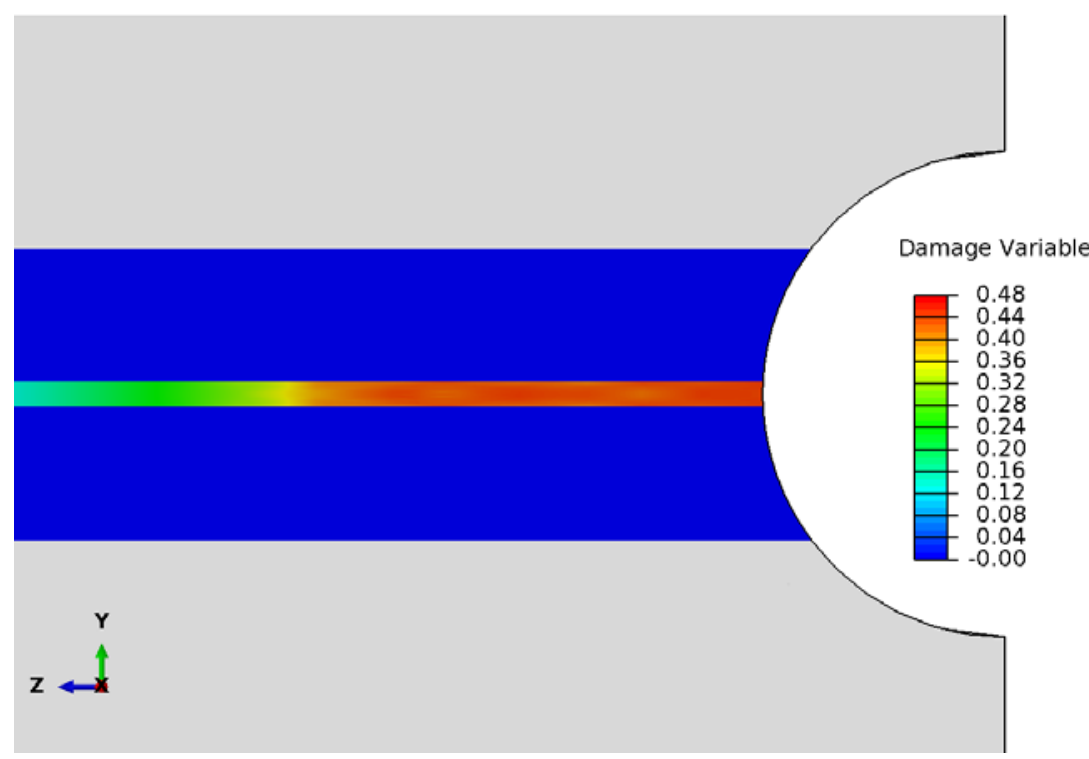

(b)

Figure 15. Predicted fracture patterns using an elastic-plastic damage model for the AV119 adhesive epoxy and for 316SS. Shown in (a) is the predicted fracture for CVD-SiC joined with AV119 where the epoxy is elastic-plastic and the CVD-SiC is elastic. Shown in (b) is the case 
for both materials obeying the elastic-plastic damage model for 316SS joined with AV119 epoxy. In all cases the failure occurs within the epoxy joint.

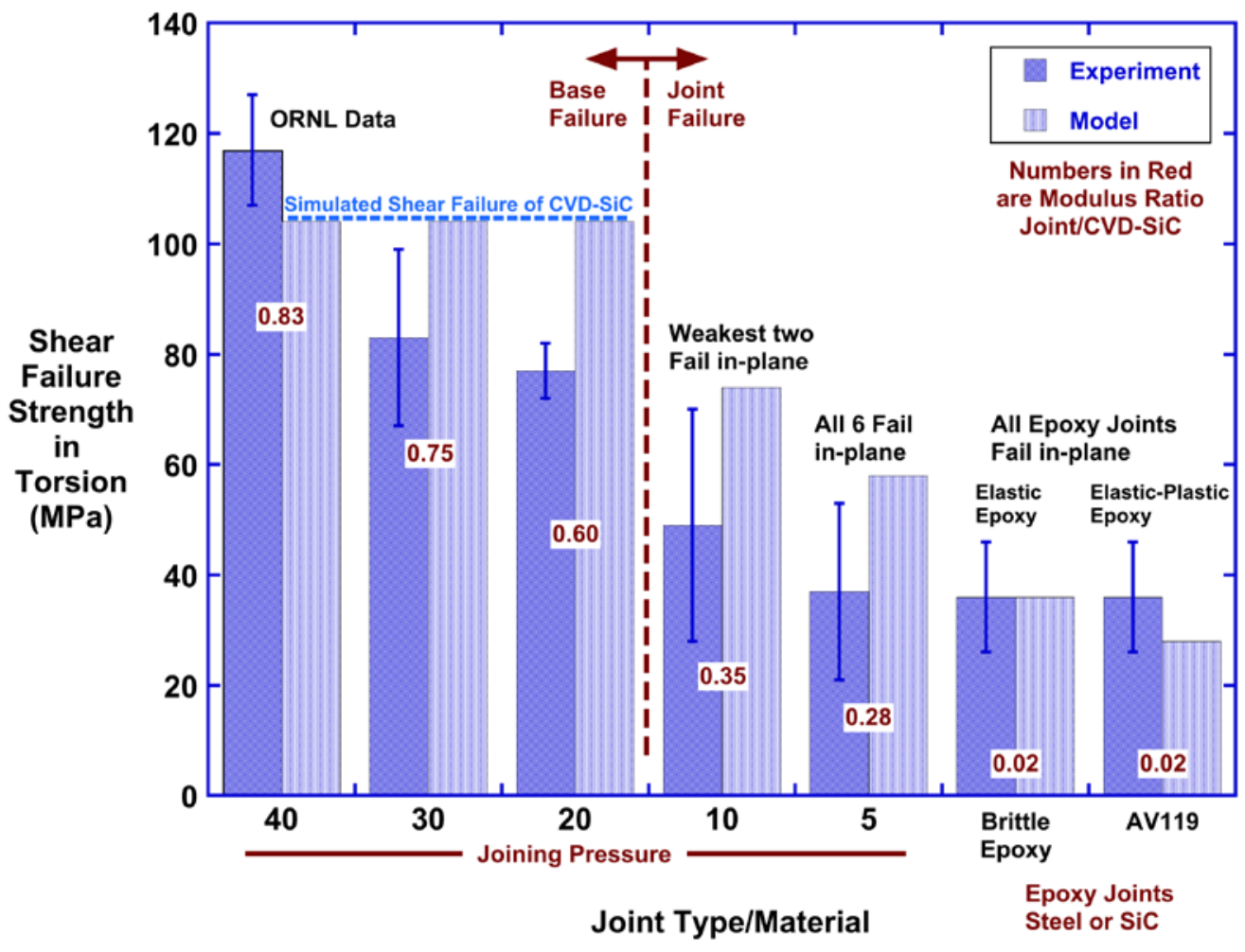

(a) 


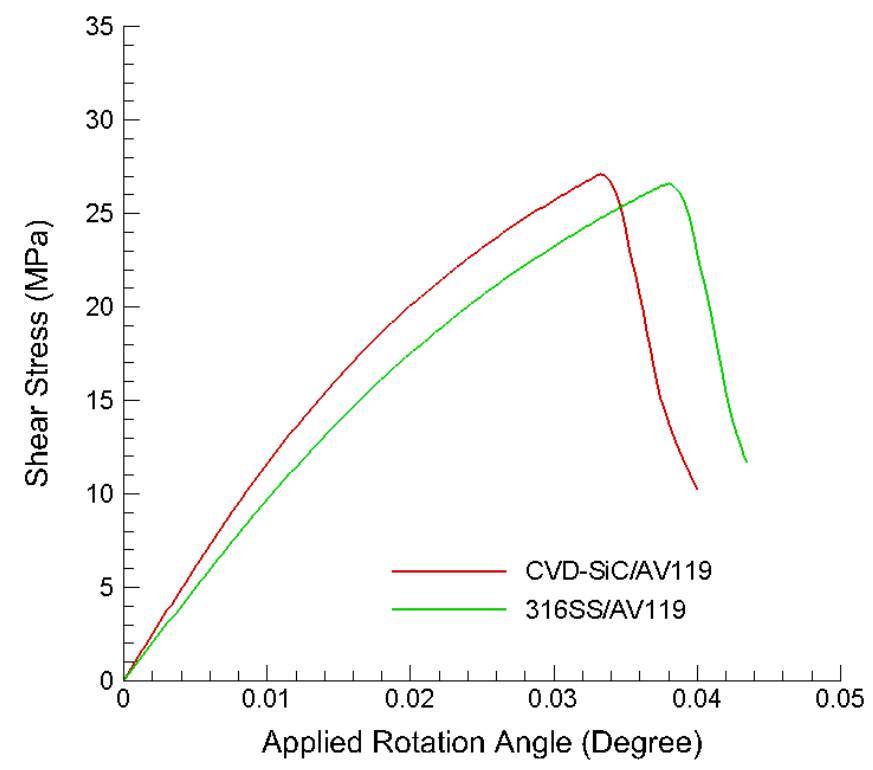

(b)

Figure 16. Graph showing the predicted maximum shear stresses at fracture in (a) for all damage model simulations compared to experimental data. The numbers in red refer to the ratio of the modulus of the joint material to that of CVD-SiC. Shown in (b) is the predicted evolution of the maximum in-plane shear stresses with applied rotation angle for the elastic-plastic AV119 cases from Fig. 15. 